Cochrane Database of Systematic Reviews

\title{
Non-steroid anti-inflammatory drugs for biliary colic (Review)
}

Fraquelli M, Casazza G, Conte D, Colli A

Fraquelli M, Casazza G, Conte D, Colli A.

Non-steroid anti-inflammatory drugs for biliary colic.

Cochrane Database of Systematic Reviews 2016, Issue 9. Art. No.: CD006390.

DOI: 10.1002/14651858.CD006390.pub2. 
TABLE OF CONTENTS

HEADER 1

ABSTRACT

PLAIN LANGUAGE SUMMARY

SUMMARY OF FINDINGS

BACKGROUND

OBJECTIVES

METHODS

RESULTS

Figure 1.

Figure 2.

Figure 3.

Figure 4.

Figure 5.

Figure 6.

Figure 7.

DISCUSSION

AUTHORS' CONCLUSIONS

ACKNOWLEDGEMENTS

REFERENCES

CHARACTERISTICS OF STUDIES

DATA AND ANALYSES

Analysis 1.1. Comparison 1 NSAIDs versus placebo, Outcome 1 Lack of pain relief.

Analysis 1.2. Comparison 1 NSAIDs versus placebo, Outcome 2 Cholelithiasis-related complications.

Analysis 2.1. Comparison 2 NSAIDs versus opioids, Outcome 1 Lack of pain relief.

Analysis 2.2. Comparison 2 NSAIDs versus opioids, Outcome 2 Cholelithiasis-related complications.

Analysis 3.1. Comparison 3 NSAIDs versus spasmolytic drugs, Outcome 1 Lack of pain relief.

Analysis 3.2. Comparison 3 NSAIDs versus spasmolytic drugs, Outcome 2 Cholelithiasis-related complications. APPENDICES

CONTRIBUTIONS OF AUTHORS

DECLARATIONS OF INTEREST

SOURCES OF SUPPORT

DIFFERENCES BETWEEN PROTOCOL AND REVIEW 
[Intervention Review]

\title{
Non-steroid anti-inflammatory drugs for biliary colic
}

\author{
Mirella Fraquelli ${ }^{1}$, Giovanni Casazza², Dario Conte ${ }^{1}$, Agostino Colli³
}

1Gastroenterology and Endoscopy Unit, Fondazione IRCCS Cà Granda - Ospedale Maggiore Policlinico, Department of Pathophysiology and Transplantation, Università degli Studi di Milano, Milan, Italy. 2Dipartimento di Scienze Biomediche e Cliniche "L. Sacco", Università degli Studi di Milano, Milan, Italy. ${ }^{3}$ Department of Internal Medicine, A Manzoni Hospital ASST Lecco, Lecco, Italy

Contact address: Mirella Fraquelli, Gastroenterology and Endoscopy Unit, Fondazione IRCCS Cà Granda - Ospedale Maggiore Policlinico, Department of Pathophysiology and Transplantation, Università degli Studi di Milano, Via F. Sforza, 35, Milan, 20122, Italy. mfraquelli@yahoo.it.

Editorial group: Cochrane Hepato-Biliary Group.

Publication status and date: New, published in Issue 9, 2016.

Citation: Fraquelli M, Casazza G, Conte D, Colli A. Non-steroid anti-inflammatory drugs for biliary colic. Cochrane Database of Systematic Reviews 2016, Issue 9. Art. No.: CD006390. DOI: 10.1002/14651858.CD006390.pub2.

Copyright @ 2016 The Cochrane Collaboration. Published by John Wiley \& Sons, Ltd.

\begin{abstract}
A B S T R A C T
Background

Cholelithiasis refers to the presence of gallstones, which are concretions that form in the biliary tract, usually in the gallbladder. Cholelithiasis is one of the most common surgical problems worldwide and is particularly prevalent in most Western countries.

Biliary colic is the term used for gallbladder pain experienced by a person with gallstones and without overt infection around the gallbladder. It is the most common manifestation of cholelithiasis, observed in over one-third of people with gallstones over the course of 10 or more years. Non-steroid anti-inflammatory drugs (NSAIDs) have been widely used to relieve biliary colic pain, but their role needs further elucidation. They may decrease the frequency of short-term complications, such as mild form of acute cholecystitis, jaundice, cholangitis, and acute pancreatitis, but they may also increase the occurrence of more severe and possibly life-threatening adverse events such as gastrointestinal bleeding, renal function impairment, cardiovascular events, or milder events such as abdominal pain, drowsiness, headache, dizziness, or cutaneous manifestations.
\end{abstract}

\section{Objectives}

To assess the benefits and harms of NSAIDs in people with biliary colic.

\section{Search methods}

We searched the Cochrane Hepato-Biliary Controlled Trials Register, Cochrane Central Register of Controlled Trials (CENTRAL) in the Cochrane Library, MEDLINE (Ovid SP), Embase (Ovid SP), Science Citation Index Expanded (Web of Science), and ClinicalTrials.gov until July 2016. We applied no language limitation.

\section{Selection criteria}

Randomised clinical trials recruiting participants presenting with biliary colic and comparing NSAIDs versus no intervention, placebo, or other drugs.

\section{Data collection and analysis}

Two review authors (MF and AC) independently identified trials for inclusion. We used risk ratios (RR) to express intervention effect estimates, and we analysed the data with both fixed-effect and random-effects model meta-analyses, depending on the amount of heterogeneity. We controlled random errors with Trial Sequential Analysis. We assessed the methodological quality of the evidence using GRADE criteria. 


\section{Main results}

Twelve randomised clinical trials (RCTs) met our predefined review protocol criteria for analysis. We found only one trial to be at low risk of bias, considering the remaining trials to be at high risk of bias. The risk of selection bias in nine studies was unclear due to poor reporting, leading to uncertainty in the pooled effect estimates. Five trials compared NSAIDs versus placebo, four trials compared NSAID versus opioids, and four trials compared NSAID versus spasmolytic drugs (one of the 12 trials was a three-arm study comparing NSAIDs versus both opioids and spasmolytic drugs). There were 828 randomised participants (minimum 30 and maximum 324 per trial), of whom 416 received NSAIDs and 412 received placebo, spasmolytic drugs, or opioids. Twenty-four per cent of the participants were males. The age of the participants in the trials ranged from 18 to 86 years. All people were admitted to emergency departments for acute biliary pain. There was no mortality. When compared with placebo, NSAIDs obtained a significantly lower proportion of participants without complete pain relief (RR $0.27,95 \%$ confidence interval $(\mathrm{Cl}) 0.19$ to $0.40 ; \mathrm{I}^{2}=0 \%$; 5 trials; moderate-quality evidence), which was confirmed by Trial Sequential Analysis, but not regarding participants with complications (RR $0.66,95 \% \mathrm{Cl} 0.38$ to $1.15 ; 1^{2}=26 \%$; 3 trials; very low-quality evidence). NSAIDs showed more pain control than spasmolytic drugs (RR $0.51,95 \% \mathrm{Cl} 0.37$ to $0.71 ; 12=0 \%$; 4 trials; low-quality evidence), which was not confirmed by Trial Sequential Analysis, and a significantly lower proportion of participants with complications (RR $0.27,95 \%$ $\mathrm{Cl} 0.12$ to $0.57 ; \mathrm{I}^{2}=0 \% ; 2$ trials; low-quality evidence), which was also not confirmed by Trial Sequential Analysis. We found no difference in the proportions of participants without complete pain relief when comparing NSAIDs versus opioids (RR $0.98,95 \% \mathrm{CI} 0.47$ to $2.07 ; \mathrm{I} 2$ $=52 \%$ ), suggesting moderate heterogeneity among trials (4 trials; very low-quality evidence). Only one trial comparing NSAIDs versus opioids reported results on complications, finding no significant difference between treatments. None of the included trials reported severe adverse events. Seven out of the 12 trials assessed non-severe adverse events: in two out of the seven trials, adverse events were not observed, and minor events were reported in the remaining five trials.

In addition, we found one ongoing RCT assessing the analgesic efficacy of intravenous ibuprofen in biliary colic.

\section{Authors' conclusions}

NSAIDs have been assessed in relatively few trials including a limited number of participants for biliary colic, considering its common occurrence. We found only one trial to be at low risk of bias. There was no mortality. None of the included trials reported quality of life. The generalisability of the review is low as most of the RCTs included neither elderly people nor participants with comorbidities, who are more prone to complications as compared to others with biliary colic.

The beneficial effect of NSAIDs compared with placebo on pain relief was confirmed when we applied Trial Sequential Analysis.

The quality of evidence according to GRADE criteria was moderate for the comparison of NSAIDs versus placebo regarding the outcome lack of pain relief and low or very low for the other outcomes and comparisons.

We found only one trial at low risk of bias, following the predefined 'Risk of bias' domains. We found the risk of selection bias to be unclear in nine studies due to poor reporting, leading to uncertainty in the pooled effect estimates.

\section{PLAIN LANGUAGE SUMMARY}

\section{Non-steroid anti-inflammatory drugs for biliary colic}

\section{Background}

Non-steroid anti-inflammatory drugs (NSAIDs) such as diclofenac, ketorolac, tenoxicam, flurbiprofen, etc. are commonly used to relieve biliary colic pain.

\section{Study characteristics}

We searched for randomised clinical trials recruiting participants presenting with biliary colic and comparing NSAIDs versus no intervention, placebo, or other drugs.

\section{Key results}

We included 12 randomised clinical trials with 828 participants, of whom 416 received NSAIDs and 412 received placebo, spasmolytic drugs, or opioids, in the review. Considering the common occurrence of biliary colic, these numbers of trials and participants are insufficient. Elderly participants and participants with co-morbidities were poorly represented in the trials. Twenty-four per cent of the participants were males. The age of participants ranged from 18 to 86 years. All people were admitted to emergency department for acute biliary pain. There was no mortality. None of the included trials reported quality of life. We found that NSAIDs significantly reduced biliary pain when compared with placebo and spasmolytic drugs. NSAIDs also significantly reduced cholelithiasis-related complications (e.g. acute cholecystitis, acute pancreatitis, jaundice, cholangitis) as compared to placebo and spasmolytic drugs. One trial comparing NSAIDs versus opioids reported results on complications, finding no significant difference between treatments.

None of the trials reported major adverse events. Seven out of 12 trials reported minor adverse events; in two out of the eight trials adverse events were not observed, and minor events were reported in the remaining five trials. 
We found one ongoing randomised clinical trial aimed at assessing the analgesic effectiveness of intravenous ibuprofen in biliary colic.

\section{Funding}

The trials appeared to be free of industry sponsorship or other type of for-profit support that may manipulate the trial design, conductance, results, or conclusions of the trial.

\section{Quality of evidence}

The quality of evidence according to GRADE criteria (a system developed to grade evidence and recommendations in health care) was moderate for the comparison NSAIDs versus placebo for the outcome lack of pain relief and low or very low for the other outcomes and comparisons.

Only one of 12 trials was at low risk of bias following predefined 'Risk of bias' domains.

The results of the present systematic review with meta-analysis suggest that NSAIDs can be used for pain relief, but further randomised clinical trials are warranted, and NSAIDs should be used with care in certain patient groups, such as the elderly and people with comorbidities. 


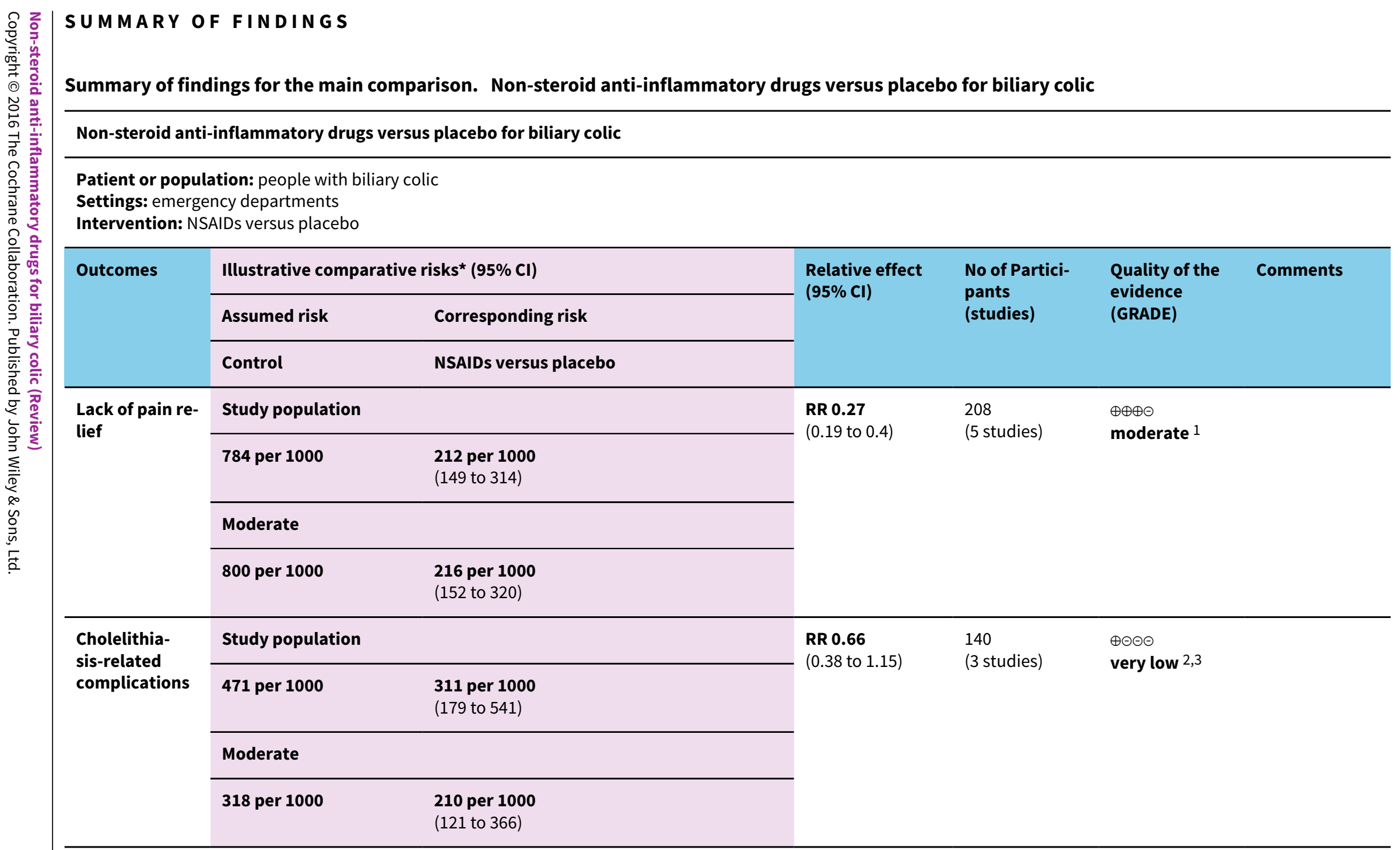

*The basis for the assumed risk (e.g. the median control group risk across studies) is provided in footnotes. The corresponding risk (and its $95 \%$ confidence interval) is based on the assumed risk in the comparison group and the relative effect of the intervention (and its $95 \% \mathrm{Cl}$ ).

CI: confidence interval; NSAIDs: non-steroid anti-inflammatory drugs; RR: risk ratio

GRADE Working Group grades of evidence

High quality: Further research is very unlikely to change our confidence in the estimate of effect.

Moderate quality: Further research is likely to have an important impact on our confidence in the estimate of effect and may change the estimate. 


\begin{tabular}{|c|c|c|c|c|c|c|}
\hline \multicolumn{7}{|c|}{$\begin{array}{l}\text { 1Downgraded one level }(-1) \text { for risk of bias because the overall risk of bias in four out of five studies was unclear. } \\
\text { 2Downgraded one level }(-1) \text { for risk of bias because the overall risk of bias in two out of three studies was unclear. } \\
\text { 3Downgraded two levels }(-2) \text { for imprecision: wide } 95 \% \mathrm{Cl} \text { overlapping } 1 \text { and including appreciable benefits }(\mathrm{RR}<0.75) \text {; the required information size was not reached. } \\
\text { Summary of findings } 2 \text {. Non-steroid anti-inflammatory drugs versus opioids for biliary colic }\end{array}$} \\
\hline \multicolumn{7}{|c|}{ Non-steroid anti-inflammatory drugs versus opioids for biliary colic } \\
\hline \multicolumn{7}{|c|}{$\begin{array}{l}\text { Patient or population: people with biliary colic } \\
\text { Settings: emergency departments } \\
\text { Intervention: NSAIDs versus opioids }\end{array}$} \\
\hline \multirow[t]{3}{*}{ Outcomes } & \multicolumn{2}{|c|}{ Illustrative comparative risks ${ }^{\star}(95 \% \mathrm{Cl})$} & \multirow{3}{*}{$\begin{array}{l}\text { Relative effect } \\
(95 \% \mathrm{Cl})\end{array}$} & \multirow{3}{*}{$\begin{array}{l}\text { No of Partici- } \\
\text { pants } \\
\text { (studies) }\end{array}$} & \multirow{3}{*}{$\begin{array}{l}\text { Quality of the } \\
\text { evidence } \\
\text { (GRADE) }\end{array}$} & \multirow[t]{3}{*}{ Comments } \\
\hline & Assumed risk & Corresponding risk & & & & \\
\hline & Control & NSAIDs versus opioids & & & & \\
\hline \multirow{4}{*}{$\begin{array}{l}\text { Lack of pain re- } \\
\text { lief }\end{array}$} & Study popula & & \multirow{4}{*}{$\begin{array}{l}\text { RR } 0.98 \\
\text { (0.47 to } 2.07)\end{array}$} & \multirow{4}{*}{$\begin{array}{l}459 \\
\text { (4 studies) }\end{array}$} & \multirow{4}{*}{\multicolumn{2}{|c|}{$\begin{array}{l}\oplus \odot \Theta \odot \\
\text { very low 1,2 }\end{array}$}} \\
\hline & 180 per 1000 & $\begin{array}{l}\mathbf{1 7 6} \text { per } \mathbf{1 0 0 0} \\
\text { (84 to } 372 \text { ) }\end{array}$ & & & & \\
\hline & \multicolumn{2}{|l|}{ Moderate } & & & & \\
\hline & 203 per 1000 & $\begin{array}{l}199 \text { per } 1000 \\
\text { (95 to } 420)\end{array}$ & & & & \\
\hline \multirow{4}{*}{$\begin{array}{l}\text { Cholelithia- } \\
\text { sis-related } \\
\text { complications }\end{array}$} & Study popula & & \multirow{4}{*}{$\begin{array}{l}\text { RR } 0.88 \\
\text { (0.14 to } 5.42)\end{array}$} & \multirow{4}{*}{$\begin{array}{l}30 \\
\text { (1 study) }\end{array}$} & \multirow{4}{*}{\multicolumn{2}{|c|}{$\begin{array}{l}\oplus \ominus \Theta \odot \\
\text { very low 2,3 }\end{array}$}} \\
\hline & 143 per 1000 & $\begin{array}{l}\mathbf{1 2 6} \text { per } 1000 \\
(20 \text { to } 774)\end{array}$ & & & & \\
\hline & \multicolumn{2}{|l|}{ Moderate } & & & & \\
\hline & 143 per 1000 & $\begin{array}{l}\mathbf{1 2 6} \text { per } \mathbf{1 0 0 0} \\
\text { (20 to } 775)\end{array}$ & & & & \\
\hline
\end{tabular}

*The basis for the assumed risk (e.g. the median control group risk across studies) is provided in footnotes. The corresponding risk (and its $95 \%$ confidence interval) is based on the assumed risk in the comparison group and the relative effect of the intervention (and its $95 \% \mathrm{Cl}$ ). 
GRADE Working Group grades of evidence

High quality: Further research is very unlikely to change our confidence in the estimate of effect.

Moderate quality: Further research is likely to have an important impact on our confidence in the estimate of effect and may change the estimate.

Low quality: Further research is very likely to have an important impact on our confidence in the estimate of effect and is likely to change the estimate.

Very low quality: We are very uncertain about the estimate.

1Downgraded one level (-1) for risk of bias because the overall risk of bias was unclear in three and high in one out of four studies.

2Downgraded two levels (-2) for imprecision: wide $95 \% \mathrm{Cl}$ including appreciable benefits and harms $(\mathrm{RR}<0.75$ and $\mathrm{RR}>1.25)$; the required information size was not reached.

3Downgraded one level (-1) for risk of bias because of only one study which is also at overall high risk of bias.

\section{Summary of findings 3. Non-steroid anti-inflammatory drugs versus spasmolytic drugs for biliary colic}

\section{Non-steroid anti-inflammatory drugs versus spasmolytic drugs for biliary colic}

Patient or population: people with biliary colic

Settings: emergency departments

Intervention: NSAIDs versus spasmolytic drugs

\begin{tabular}{|c|c|c|c|c|c|c|}
\hline \multirow[t]{3}{*}{ Outcomes } & \multicolumn{2}{|c|}{ Illustrative comparative risks ${ }^{\star}(95 \% \mathrm{Cl})$} & \multirow{3}{*}{$\begin{array}{l}\text { Relative effect } \\
(95 \% \mathrm{Cl})\end{array}$} & \multirow{3}{*}{$\begin{array}{l}\text { No of Partici- } \\
\text { pants } \\
\text { (studies) }\end{array}$} & \multirow{3}{*}{$\begin{array}{l}\text { Quality of the } \\
\text { evidence } \\
\text { (GRADE) }\end{array}$} & \multirow[t]{3}{*}{ Comments } \\
\hline & Assumed risk & Corresponding risk & & & & \\
\hline & Control & NSAIDs versus spasmolytic drugs & & & & \\
\hline \multirow{4}{*}{$\begin{array}{l}\text { Lack of pain re- } \\
\text { lief }\end{array}$} & \multicolumn{2}{|c|}{ Study population } & \multirow{4}{*}{$\begin{array}{l}\mathbf{R R} \mathbf{0 . 5 1} \\
(0.37 \text { to } 0.71)\end{array}$} & \multirow{4}{*}{$\begin{array}{l}190 \\
\text { (4 studies) }\end{array}$} & \multirow{4}{*}{$\begin{array}{l}\oplus \oplus \Theta \Theta \\
\text { low } 1,2\end{array}$} & \\
\hline & 598 per 1000 & $\begin{array}{l}\mathbf{3 0 5} \text { per } 1000 \\
\text { (221 to } 424)\end{array}$ & & & & \\
\hline & \multicolumn{2}{|l|}{ Moderate } & & & & \\
\hline & 615 per 1000 & $\begin{array}{l}\mathbf{3 1 4} \text { per } \mathbf{1 0 0 0} \\
\text { (228 to } 437)\end{array}$ & & & & \\
\hline \multirow{3}{*}{$\begin{array}{l}\text { Cholelithia- } \\
\text { sis-related } \\
\text { complications }\end{array}$} & \multicolumn{2}{|c|}{ Study population } & \multirow{3}{*}{$\begin{array}{l}\text { RR } \mathbf{0 . 2 7} \\
(0.12 \text { to } 0.57)\end{array}$} & \multirow{3}{*}{$\begin{array}{l}104 \\
\text { (2 studies) }\end{array}$} & \multirow{3}{*}{$\begin{array}{l}\oplus \oplus \ominus \ominus \\
\text { low } 1,2\end{array}$} & \\
\hline & 462 per 1000 & $\begin{array}{l}\mathbf{1 2 5} \text { per } 1000 \\
\text { (55 to } 263)\end{array}$ & & & & \\
\hline & \multicolumn{2}{|l|}{ Moderate } & & & & \\
\hline
\end{tabular}


*The basis for the assumed risk (e.g. the median control group risk across studies) is provided in footnotes. The corresponding risk (and its $95 \%$ confidence interval) is based on the assumed risk in the comparison group and the relative effect of the intervention (and its $95 \% \mathrm{Cl}$ ).

CI: confidence interval; NSAIDs: non-steroid anti-inflammatory drugs; RR: risk ratio

GRADE Working Group grades of evidence

High quality: Further research is very unlikely to change our confidence in the estimate of effect.

Moderate quality: Further research is likely to have an important impact on our confidence in the estimate of effect and may change the estimate.

Low quality: Further research is very likely to have an important impact on our confidence in the estimate of effect and is likely to change the estimate.

Very low quality: We are very uncertain about the estimate.

1Downgraded one level (-1) for risk of bias because the overall risk of bias was unclear in all the studies.

2Downgraded one level (-1) for imprecision: the required information size was not reached. 


\section{B A C K G R O U N D}

\section{Description of the condition}

Cholelithiasis refers to the presence of gallstones, which are concretions that form in the biliary tract, usually in the gallbladder. Cholelithiasis represents one of the most common surgical problems worldwide and is especially prevalent in most Western countries. In the USA alone, gallstones are present in $8 \%$ to $20 \%$ of the population by the age of 40 years, and are more likely to develop in women than in men by a ratio of between 2 and 3 to 1 (Friedman 1993; Johnson 2001). Mexican-Americans and American Indians also seem to have an increased risk for the development of gallstones, and in all cultures, the incidence increases as age increases.

A population of male civil servants in Rome, Italy, was investigated to determine the prevalence of symptomatic and asymptomatic gallstone disease. In this study, in which $71.5 \%$ of the population participated, the prevalence of gallstone disease was $8.2 \%$, and increased from $2.3 \%$ in the 20 - to 25 -year-old age group to $14.4 \%$ in the 60- to 69-year-old age group, based on both presence of gallstones and history of cholecystectomy. About one-third of the men with gallstone disease had previously been submitted to cholecystectomy. Overall, $7.7 \%$ of the men with presence of gallstones had complained of at least one episode of biliary pain in the preceding five years (Grepco | 1988). In another, more recent study performed in a random sample of women belonging to a rural population, during a 10-year longitudinal follow-up, the overall 10-year incidence of gallstone disease was $6.3 \%$ (5.5\% of new gallstones and $0.8 \%$ of cholecystectomies) (Angelico 1997). More than three-quarters (76.9\%) of these women had not suffered biliary pain (Angelico 1997). Out of the initially asymptomatic gallstone women, $15.4 \%$ experienced at least one episode of biliary pain, $23.1 \%$ underwent elective cholecystectomy, and $61.5 \%$ remained asymptomatic (Grepco II 1988). The GREPCO study reported a cumulative probability of developing biliary colic in initially asymptomatic people of $11.9 \pm 3.0 \%$ at two years and 25.8 $\pm 4.6 \%$ at 10 years (Attili 1995).

\section{Description of the intervention}

Non-steroid anti-inflammatory drugs (NSAIDs), opioid drugs, and spasmolytic drugs have been widely used to relieve biliary colic. NSAIDs are usually used as the first line of treatment.

\section{How the intervention might work}

NSAIDs' pathophysiological mechanism of relieving pain is thought to be related not only to their anti-inflammatory action, but also to their smooth-muscle relaxant capacities (Thornell 1985; Goldman 1989; Brooks 1998; Morgan 1999). However, the actual role of NSAIDs in biliary colic has yet to be clarified. It remains unclear whether NSAIDs decrease or increase the frequency of short-term complications caused by gallstones. Simultaneously, NSAIDs may increase the risk for more severe adverse events, including those that are life-threatening. For instance, NSAIDs interfere with platelet function, and thus may increase the risk of bleeding after interventions such as surgery or endoscopic retrograde cholangiopancreatography (ERCP).

The usual first-line treatment for biliary colic is NSAIDs, but other drugs can also be used. Opioid drugs include morphine, codeine, and pethidine, which reduce the intensity of pain signals reaching the brain and affect those brain areas that control emotion, in this way diminishing the effects of a painful stimulus. Spasmolytic drugs such as hyoscine butylbromide (also known as scopolamine) inhibit the action of acetylcholine and stop the transmission of parasympathetic nerve impulses, thus lessening the spasms of the smooth muscle in the gastrointestinal tract and in the gallbladder.

\section{Why it is important to do this review}

Cholelithiasis is one of the most common surgical problems worldwide and is especially prevalent in Western countries. Biliary colic is the most common manifestation of cholelithiasis, developing in at least one-third of people with gallbladder stones over a 10-year follow-up period. NSAIDs have been widely used to relieve biliary colic pain, but their role needs further elucidation. NSAIDs may decrease the frequency of short-term complications caused by gallstones, such as a mild form of acute cholecystitis, jaundice, cholangitis, and acute pancreatitis, but they may simultaneously increase the risk of more severe and possibly life-threatening events such as gastrointestinal bleeding, renal function impairment, cardiovascular events, or milder events such as abdominal pain, drowsiness, headache, dizziness, or cutaneous manifestations.

There are only two non-Cochrane systematic reviews with metaanalyses so far available. The first Spanish review compared NSAIDs versus other drugs for biliary colic in people with cholelithiasis (Basurto Ona 2008), and included seven randomised clinical trials with 349 participants (Niinikoski 1984; Grossi 1986; Camp 1992; Al Waili 1998; Dula 2001; Goldman 2001; Kumar 2004); all but one of these trials are included in our review (Niinikoski 1984). We excluded Niinikoski 1984 from our review because it compared two NSAIDs (indomethacin $50 \mathrm{mg}$ and metamizole $2.5 \mathrm{~g}$ ). The second non-Cochrane review was published by our own group (Colli 2012). In this review, we did not grade the overall evidence and did not perform a Trial Sequential Analysis to calculate the cumulative sample size of the meta-analysis (information size), thus running the risk of overestimating the efficacy of NSAIDs in reducing biliary colic complications.

\section{O B JECTIVES}

To assess the benefits and harms of NSAIDs in people with biliary colic.

\section{METHOD S}

\section{Criteria for considering studies for this review \\ Types of studies}

Randomised clinical trials evaluating the possible benefits and harms of NSAIDs in people with biliary colic. We included the trials irrespective of blinding, year of publication, publication status, or language.

For evaluation of harms, we included quasi-randomised clinical studies and observational studies identified during our searches for randomised clinical trials.

\section{Types of participants}

All people presenting with biliary colic according to the definitions and diagnostic work-up in the individual trials. 


\section{Types of interventions}

We considered all types of NSAIDs as the experimental intervention. We considered no intervention, placebo, or other drugs (e.g. opioid, spasmolytic drugs) as control interventions, independently of their route or schedule of administration.

We allowed collateral interventions if received equally by all participants in the trial.

\section{Types of outcome measures}

\section{Primary outcomes}

1. Mortality.

2. Lack of pain relief. Number of people not experiencing pain relief out of all the people treated as defined in the primary studies.

\section{Secondary outcomes}

1. Number of people with cholelithiasis-related complications (e.g. acute cholecystitis, acute pancreatitis, jaundice, cholangitis; number of people manifesting bleeding from operative intervention or ERCP less than 9, or both).

2. Quality of life.

3. Drug-related complications and adverse events, the latter expressed as the number of people experiencing any event (e.g. gastrointestinal bleeding, cutaneous rash, renal function impairment, cardiovascular events, or any other events described in the trials).

4. Quantification of pain relief rated in the trials on quantitative scales.

5. The time needed to obtain pain relief: complete pain relief or any small amount of pain relief (as defined by the different trials).

\section{Search methods for identification of studies}

\section{Electronic searches}

We searched the Cochrane Hepato-Biliary Group Controlled Trials Register (Gluud 2016; 31 July 2016), Cochrane Central Register of Controlled Trials (CENTRAL; 2016, Issue 5) in the Cochrane Library, MEDLINE (OvidSP; 1946 to 31 July 2016), Embase (OvidSP; 1974 to 31 July 2016), Science Citation Index Expanded (Web of Science; 1900 to 31 July 2016) (Royle 2003), and ClinicalTrials.gov (www.clinicaltrials.gov) (31 July 2016). We also searched ClinicalTrials.gov for ongoing studies. The search strategies used and time spans of the searches can be found in Appendix 1.

\section{Searching other resources}

We searched the proceedings of the major hepatological and surgical congresses and references of included trials. In cases where the full paper could not be retrieved or there were uncertainties, we contacted the authors of the study.

\section{Data collection and analysis}

\section{Selection of studies}

Two review authors (MF, AC) read the abstract of each study identified by the search, eliminated studies that clearly did not satisfy the inclusion criteria, and obtained full copies of the remaining studies. The same review authors then independently read these studies to determine eligibility; any disagreements were settled by discussion, and reasons for exclusion were recorded. The two review authors were unblinded with regard to the names of the authors, investigators, institution, source, and results.

\section{Data extraction and management}

We designed standardised extraction sheets and piloted one before use. Two review authors (AC, MF) independently extracted data from the included trials. The extracted data included:

- participant characteristics: age, sex;

- experimental and control interventions (see above);

- outcomes (see above);

- trial quality characteristics (see below).

\section{Assessment of risk of bias in included studies}

Two review authors (MF, GC) independently assessed the risk of bias of each included trial according to the recommendations in the Cochrane Handbook for Systematic Reviews of Interventions (Higgins 2011), the Cochrane Hepato-Biliary Group Module (Gluud 2016), and methodological studies (Schulz 1995; Moher 1998; Kjaergard 2001; Wood 2008; Lundh 2012; Savović 2012; Savović 2012a).

We used the following definitions in the 'Risk of bias' assessment.

\section{Allocation sequence generation}

- Low risk of bias: sequence generation was achieved using computer random number generation or a random number table. Drawing lots, tossing a coin, shuffling cards, and throwing dice were adequate if performed by an independent person not otherwise involved in the trial.

- Uncertain risk of bias: the method of sequence generation was not specified.

- High risk of bias: the sequence generation method was not random.

\section{Allocation concealment}

- Low risk of bias: the participant allocations could not have been foreseen in advance of, or during, enrolment. Allocation was controlled by a central and independent randomisation unit. The allocation sequence was unknown to the investigators (e.g. if the allocation sequence was hidden in sequentially numbered, opaque, and sealed envelopes).

- Uncertain risk of bias: the method used to conceal the allocation was not described so that intervention allocations may have been foreseen in advance of, or during, enrolment.

- High risk of bias: the allocation sequence was likely to be known to the investigators who assigned the participants.

\section{Blinding of participants and personnel}

- Low risk of bias: it was mentioned that both participants and personnel providing the interventions were blinded, and the method of blinding was described, so that knowledge of allocation was prevented during the trial.

- Unclear risk of bias: it was not mentioned if the trial was blinded, or the trial was described as blinded, but the method or extent of blinding was not described, so that knowledge of allocation was possible during the trial.

- High risk of bias: the trial was not blinded, so that the allocation was known during the trial. 


\section{Blinded outcome assessment}

- Low risk of bias: it was mentioned that outcome assessors were blinded, and the method of blinding was described, so that knowledge of allocation was prevented during the trial.

- Unclear risk of bias: it was not mentioned if the trial was blinded, or the trial was described as blinded, but the method or extent of blinding the assessors was not described, so that knowledge of allocation was possible during the trial.

- High risk of bias: the trial was not blinded, so that the allocation was known to the assessors during the trial.

\section{Incomplete outcome data}

- Low risk of bias: missing data were unlikely to make treatment effects depart from plausible values. Sufficient methods, such as multiple imputation, were employed to handle missing data.

- Uncertain risk of bias: there was insufficient information to assess whether missing data in combination with the method used to handle missing data were likely to induce bias on the results.

- High risk of bias: the results were likely to be biased due to missing data.

\section{Selective outcome reporting}

- Low risk: the trial reported outcomes such as mortality; lack of complete pain relief; and number of people with cholelithiasisrelated complications, drug-related complications, and adverse events. If the original trial protocol was available, the outcomes should be those called for in that protocol. If the trial protocol was obtained from a trial registry (e.g. ClinicalTrials.gov), the outcomes sought should have been those enumerated in the original protocol if the trial protocol was registered before or at the time that the trial was begun. If the trial protocol was registered after the trial was begun, those outcomes will not be considered to be reliable.

- Unclear risk: not all predefined outcomes were reported fully, or it was unclear whether data on these outcomes were recorded or not.

- High risk: one or more predefined outcomes were not reported.

\section{For-profit bias}

- Low risk of bias: the trial appeared to be free of industry sponsorship or other type of for-profit support that could manipulate the trial design, conductance, or results of the trial.

- Uncertain risk of bias: the trial may or may not be free of for-profit bias, as no information on clinical trial support or sponsorship was provided.

- High risk of bias: the trial was sponsored by industry or received other type of for-profit support.

\section{Other sources of bias}

- Low risk of bias: the trial appeared to be free of other factors that could put it at risk of bias.

- Uncertain risk of bias: the trial may or may not have been free of other factors that could put it at risk of bias.

- High risk of bias: there were other factors in the trial that could put it at risk of bias.
Review authors MF and AC judged trials to be at low risk of bias if they were assessed as having low risk of bias in all of the above domains. In all other cases, we judged the trials to be at high risk of bias. We resolved any differences in opinion through discussion; in the case of unsettled disagreements, review authors GC and DC adjudicated.

We summarised results in both a 'Risk of bias' graph and a 'Risk of bias' summary.

\section{Measures of treatment effect}

We presented dichotomous data as risk ratio (RR) with 95\% confidence interval $(\mathrm{Cl})$ and continuous outcomes as mean differences (MD) with $95 \% \mathrm{Cl}$.

\section{Unit of analysis issues}

The randomised participants in the trials.

\section{Dealing with missing data}

We contacted investigators of the trials to request missing data. We performed all analyses according to the intention-to-treat analysis method, that is analysing participants in the trials in the groups to which they were randomised, regardless of whether they had received or adhered to the allocated intervention.

\section{Assessment of heterogeneity}

We explored the presence of statistical heterogeneity by the $\mathrm{Chi}^{2}$ test, with significance set at $P$ value of less than 0.10 . In case of significant heterogeneity, we explored the possible sources of heterogeneity by means of sensitivity analyses. In addition, we used the $\mathrm{I}^{2}$ statistic to quantify the heterogeneity according to the following classification: from $0 \%$ to $40 \%$, heterogeneity may not be important; from $30 \%$ to $60 \%$, heterogeneity may be moderate; from $50 \%$ to $90 \%$, heterogeneity may be substantial; and from $75 \%$ to $100 \%$, heterogeneity may be considerable.

\section{Assessment of reporting biases}

For any considered outcome where at least 10 trials were included in the meta-analysis, we tested for funnel plot asymmetry (Higgins 2011).

\section{Data synthesis}

\section{Meta-analysis}

We performed meta-analyses following the recommendations reported in the Cochrane Handbook for Systematic Reviews of Intervention and the Cochrane Hepato-Biliary Group Module (Higgins 2011; Gluud 2016).

We applied both fixed-effect model, DeMets 1987, and randomeffects model, DerSimonian 1986, meta-analyses. If there were statistically significant discrepancies in the results, we reported both analyses. Otherwise, we reported the results obtained with the fixed-effect model when heterogeneity was substantially absent ( 12 less than $10 \%)$ and reported the results obtained by the random-effects model when heterogeneity was present.

We used the statistical package provided with Review Manager 5 for the meta-analysis (RevMan 2014). 


\section{Trial Sequential Analysis}

We performed Trial Sequential Analysis to calculate the cumulative sample size of the meta-analysis (information size) and to reduce the risk of random errors due to sparse data and repetitive testing of the accumulating data (Wetterslev 2008; Wetterslev 2009; Thorlund 2011). When conducting a meta-analysis, significance testing may be performed each time a new trial is added. Similar to multiple interim analyses in a single clinical trial, repetitive testing in a meta-analysis increases the risk of type I error. The assumption underlying Trial Sequential Analysis is that testing for significance may be performed each time a new trial is added to the meta-analysis, resulting in an increased risk of random errors. For this reason, a statistical approach that controls the overall risk of type I error is needed. We calculated the information size adjusted for heterogeneity (diversity, $D^{2}$ ) between trials using the following parameters (Wetterslev 2009): the proportion of events in the control group estimated from the included trials (overall mean value); anticipated intervention effect (relative risk reduction, RRR) of 20\%; risk of type I error ( $\alpha$ ) of 0.05 ; power of 0.80 . We added trials to the analysis according to the year of publication. If more than one trial was published in a year, we added the trials in alphabetical order, according to the name of the first author. On the basis of the required information size, we constructed the trial sequential monitoring boundaries for benefits and futility using the O'Brien-Fleming alpha spending (for benefit) and beta-spending (for futility) functions. The boundaries for benefit are used in case of meta-analyses that have not reached the required information size to conclude when statistical significance is reached. If the trial sequential monitoring boundary is crossed before the required information size is reached, a sufficient level of evidence is reached, the results of the meta-analysis can be considered conclusive if bias can be excluded, and no additional trials may be needed. Conversely, if the boundary is not crossed, the meta-analysis is inconclusive, and more trials may be needed in order to detect or reject a certain intervention effect. When the cumulative Z-curve crosses the futility boundaries, a sufficient level of evidence is reached that the two treatments do not differ more than 20\% (the anticipated intervention effect used in information size estimation), and no additional trials may be needed. In all situations where no trial sequential monitoring boundaries are reached, further studies may be needed until the information size is reached or monitoring boundaries are crossed.

We performed Trial Sequential Analysis with the Trial Sequential Analysis software, version 0.9 beta (TSA 2011).

\section{Subgroup analysis and investigation of heterogeneity}

We considered the following for subgroup analyses.

- Sex.

- Participant age.

- Number of biliary colic attacks experienced before entry.

- Setting in which the trial was done (i.e. emergency unit or primary, secondary, or tertiary care unit).

- Type of NSAIDs used in the trial.

- Dosage of anti-inflammatory drug used in the trial.

- Route of administration of the drug.

- Duration of follow-up.

- Risk of bias.

\section{Sensitivity analysis}

We planned no sensitivity analyses.

\section{'Summary of findings' table}

The 'Summary of findings' tables show the proportion of people with lack of pain relief for the three comparisons that have been analysed (NSAIDs versus placebo; NSAIDs versus spasmolytic drugs; NSAIDs versus opioid drugs) and their corresponding RR (with their 95\% Cl), and the proportion of people with cholelithiasis-related complications only for the comparison NSAIDs versus placebo, with its corresponding RR $(95 \% \mathrm{CI})$.

We used the GRADE system to assess the quality of evidence and to build the 'Summary of findings' tables for the outcomes considered in this review. We used the GRADEpro 3.6 software (tech.cochrane.org/revman/gradepro) to construct Summary of findings for the main comparison, Summary of findings 2, and Summary of findings 3 . The GRADE approach appraises the quality of a body of evidence based on the extent to which one can be confident that an estimate of effect or association reflects the item being assessed. The quality of a body of evidence considers withinstudy risk of bias, indirectness of the evidence, heterogeneity of the data, imprecision of effect estimates (wide $\mathrm{Cl}$ s and as evaluated with our Trial Sequential Analysis) (Jakobsen 2014), and risk of publication bias (Guyatt 2008; Balshem 2011; Guyatt 2011; Guyatt 2011a; Guyatt 2011b; Guyatt 2011c; Guyatt 2011d; Guyatt 2011e; Guyatt 2011f; Guyatt 2011g; Guyatt 2013; Mustafa 2013; Guyatt 2013a; Guyatt 2013b; Guyatt 2013c).

We defined the levels of evidence as 'high', 'moderate', 'low', or 'very low' as follows.

- High certainty: this research provides a very good indication of the likely effect; the likelihood that the effect will be substantially different is low.

- Moderate certainty: this research provides a good indication of the likely effect; the likelihood that the effect will be substantially different is moderate.

- Low certainty: this research provides some indication of the likely effect; however, the likelihood that it will be substantially different is high.

- Very low certainty: this research does not provide a reliable indication of the likely effect; the likelihood that the effect will be substantially different is very high.

\section{RE S U L T S}

\section{Description of studies}

\section{Results of the search}

We identified a total of 278 references through electronic searches of the Cochrane Hepato-Biliary Controlled Trials Register, the Cochrane Central Register of Controlled Trials (CENTRAL), MEDLINE, Embase, and Science Citation Index Expanded until 31 July 2016. We identified two publications through manual searching. Overall, we excluded 266 references: 264 were clearly irrelevant to the present systematic review, having read abstracts in 258 cases and the full text of six of these publications, two were duplicates. We have listed the six excluded studies in the Characteristics of excluded studies table with reasons for exclusion. A PRISMA flow diagram is provided in Figure 1. 
Figure 1. Flow diagram.

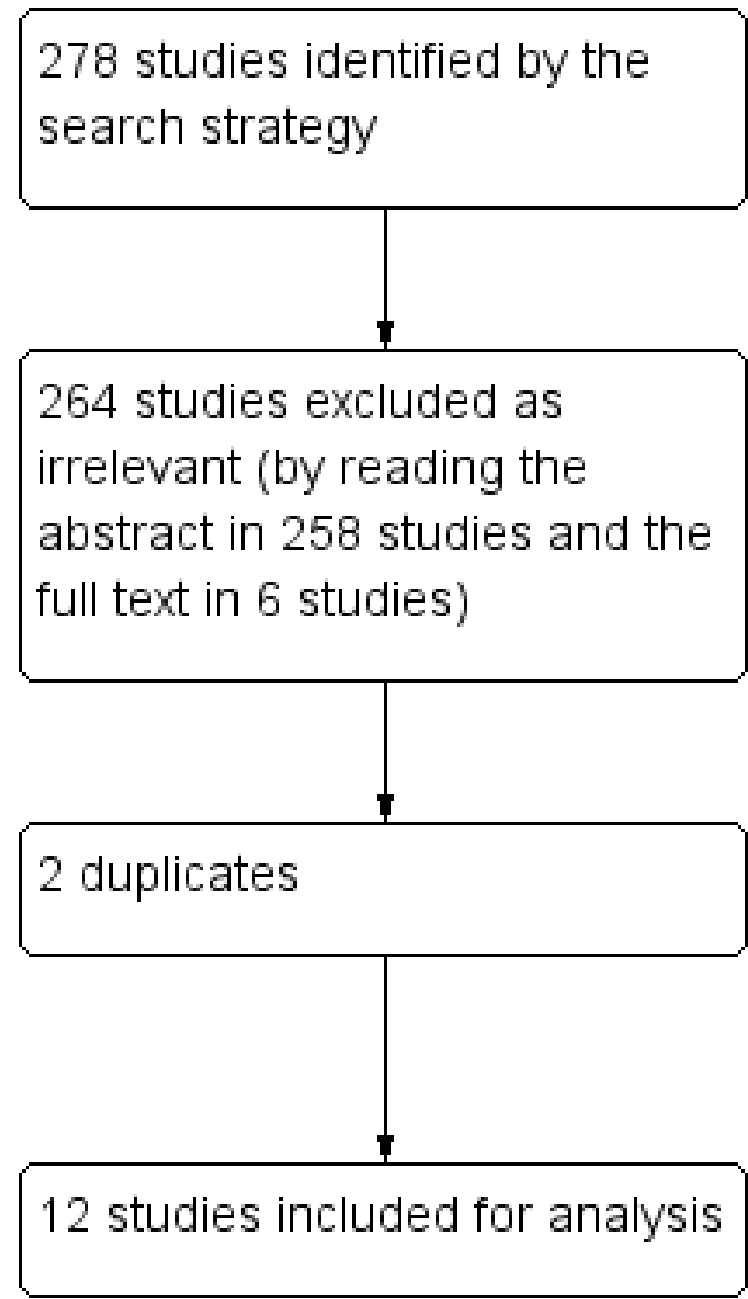

The remaining 12 references were reports of 12 randomised trials, and they fulfilled our inclusion criteria. The trials included a total of 828 participants, of whom 416 received NSAIDs and 412 served as controls (receiving placebo or opioids or spasmolytic drugs). We have provided details of the included trials in Included studies. All trials used a parallel-group design. One of the trials had three parallel groups.

We also found one ongoing study that aims to assess the analgesic efficacy of intravenous ibuprofen in biliary colic.

\section{Included studies}

We have provided a detailed description of the included trials in the Characteristics of included studies table.

\section{Trials}

All of the included trials were randomised clinical trials with parallel-group design. In one of the included trials (Camp 1992), NSAIDs were compared with both opioids and spasmolytic drugs.
1 ongoing study identified on clinicaltrials.gov

\section{Comparator interventions}

\section{NSAIDs versus placebo}

Four trials used $50 \mathrm{mg}$ to $75 \mathrm{mg}$ diclofenac (Broggini 1984; Lundstam 1985; Akriviadis 1997; Goldman 2001), and one trial used ketoprofen versus placebo (Magrini 1985).

\section{NSAIDs versus opioids}

Three trials compared ketorolac (Dula 2001; Henderson 2002; Olsen 2008), and one trial compared flurbiprofen with opioids (Camp 1992).

\section{NSAIDs versus spasmolytic drugs}

Two trials compared diclofenac (Grossi 1986; Kumar 2004), one trial compared tenoxicam (Al Waili 1998), and one trial compared flurbiprofen with spasmolytic drugs (hyoscine butylbromide) (Camp 1992).

\section{Participants}

The 12 trials randomised a total of 828 people (minimum 30 and maximum 324 per trial). Twenty-four per cent of the participants were males.The age of participants in the trials ranged from 18 to 86 
years. All participants were admitted to the emergency department for acute biliary pain.

Age lower than 65 years represented an exclusion criteria in three trials (Dula 2001; Henderson 2002; Olsen 2008), and the presence of co-morbidities such as diabetes mellitus, cardiovascular, or respiratory diseases represented an exclusion criteria in one trial (Kumar 2004). In the Henderson trial, the presence of renal insufficiency represented another exclusion criteria in addition to age (Henderson 2002).

\section{Comparator interventions}

Five trials used placebo (Broggini 1984; Lundstam 1985; Magrini 1985; Akriviadis 1997; Goldman 2001), four trials used opioids (Camp 1992; Dula 2001; Henderson 2002; Olsen 2008), and four trials used spasmolytic drugs in the control group (Grossi 1986; Camp 1992; Al Waili 1998; Kumar 2004). In one of the included trials, NSAIDs were compared with both opioids and spasmolytic drugs (Camp 1992).

We identified one ongoing trial entitled "Analgesic efficacy of intravenous ibuprofen in biliary colic" by searching
ClinicalTrials.gov, which is currently recruiting participants (NCT02268955).

\section{Excluded studies}

See Characteristics of excluded studies.

We excluded six studies for the following reasons (Thornell 1979; Niinikoski 1984; Kantor 1986; Marsala 1986: Chaudhary 1999; Chang 2002): one study was not a randomised clinical trial (Thornell 1979), one study compared two different types of NSAIDs (Niinikoski 1984), one was a review (Chang 2002), one study compared two different modalities of sodium naproxen administration (intravenous versus intramascular) (Marsala 1986), one used an association of NSAIDs administered together (Chaudhary 1999), and one used NSAID for dental pain (Chang 2002).

\section{Risk of bias in included studies}

Overall, we judged all but one trial comparing NSAIDs versus placebo to be at low risk of bias (Akriviadis 1997) (Figure 2; Figure 3). 
Figure 2. Methodological quality summary: review authors' judgements about each methodological quality item for each included study.

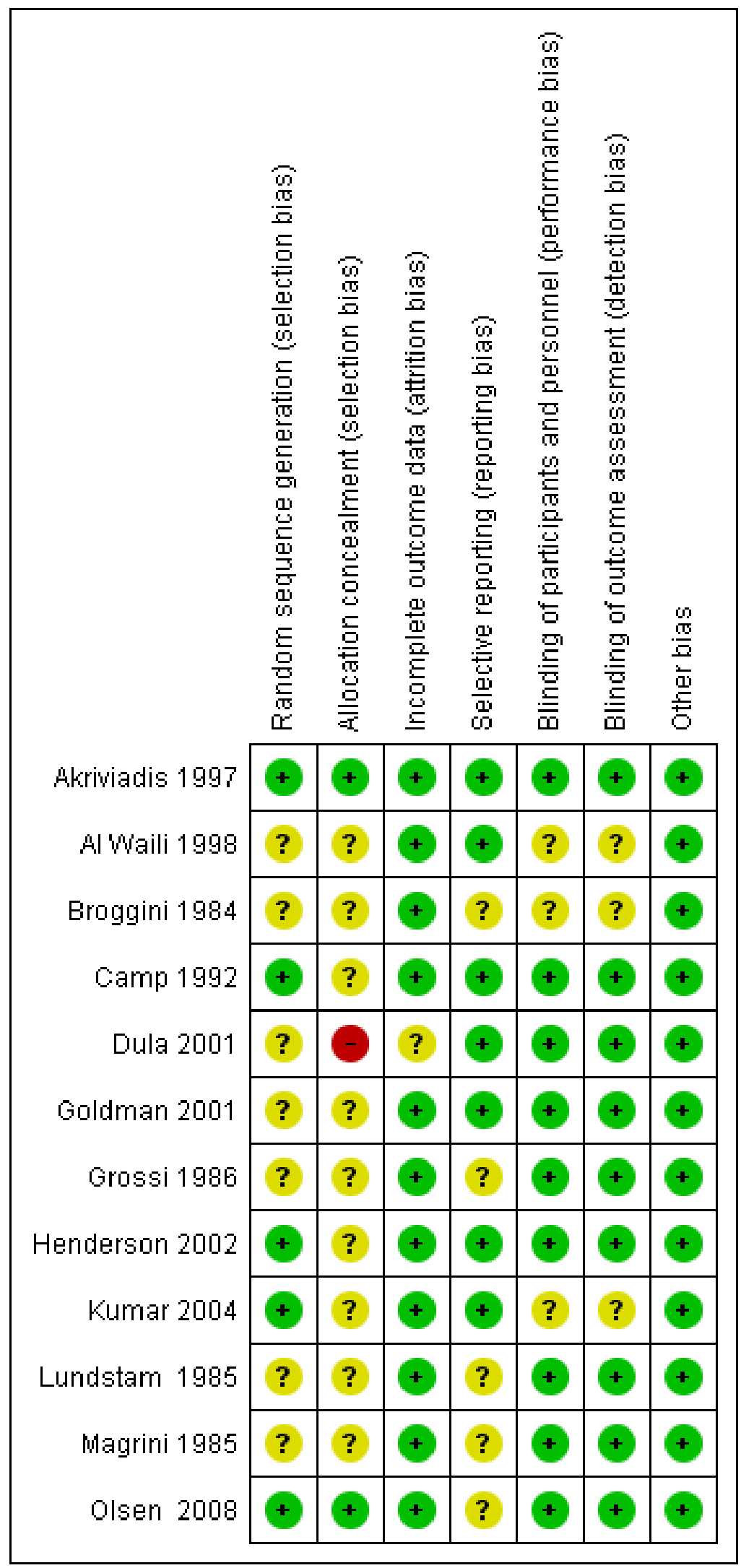


Figure 3. Risk of bias graph: review authors' judgements about each risk of bias item presented as percentages across all included studies.

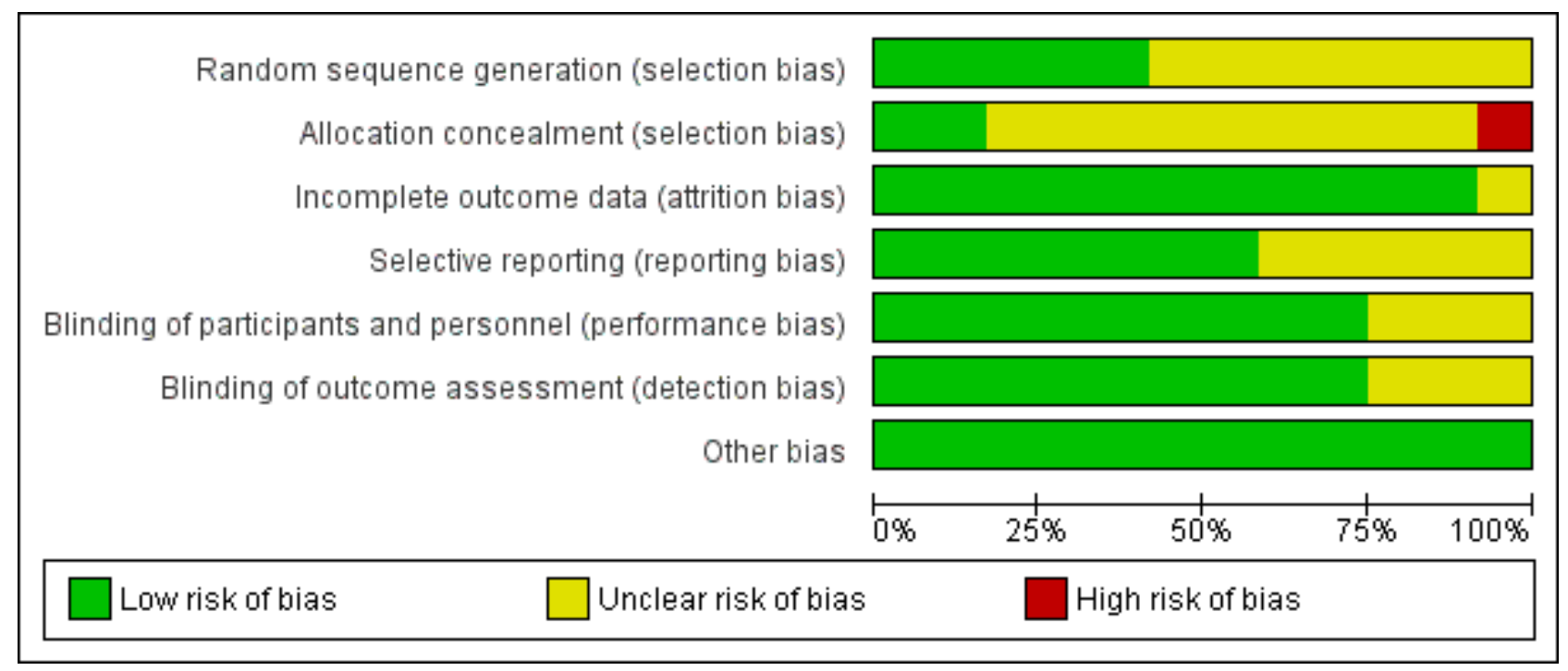

\section{Allocation}

We judged five trials as at low risk of bias (Akriviadis 1997; Camp 1992; Henderson 2002; Kumar 2004; Olsen 2008), and the other seven as at unclear risk of bias for the domain allocation sequence generation (Broggini 1984; Lundstam 1985; Magrini 1985; Grossi 1986; Goldman 2001; Al Waili 1998; Dula 2001).

Allocation concealment was adequately performed in two trials (Akriviadis 1997; Olsen 2008), inadequately performed in one trial (Dula 2001), and unclear in the remaining nine trials (Broggini 1984; Lundstam 1985; Magrini 1985; Grossi 1986; Camp 1992; Al Waili 1998; Goldman 2001; Henderson 2002; Kumar 2004).

\section{Blinding}

We considered nine trials as at low risk of bias (Lundstam 1985; Magrini 1985; Grossi 1986; Camp 1992; Akriviadis 1997; Dula 2001; Goldman 2001; Henderson 2002; Olsen 2008), and three as at unclear risk of bias regarding both blinding of participants and personnel and blinding of outcome assessment (Broggini 1984; Al Waili 1998; Kumar 2004).

\section{Incomplete outcome data}

Eleven trials were at low risk of bias (Broggini 1984; Lundstam 1985; Magrini 1985; Grossi 1986; Camp 1992; Akriviadis 1997; Al Waili 1998; Goldman 2001; Henderson 2002; Kumar 2004; Olsen 2008), and one trial was at unclear risk of bias for incomplete outcome data (Dula 2001).

\section{Selective reporting}

Seven trials were at low risk of bias (Camp 1992; Akriviadis 1997; Al Waili 1998; Dula 2001; Goldman 2001; Henderson 2002; Kumar 2004), and five trials were at unclear risk for selective outcome reporting (Broggini 1984; Lundstam 1985; Magrini 1985; Grossi 1986; Olsen 2008).

\section{Other potential sources of bias}

We observed no risk of for-profit bias on the side of researchers, industries, or funding bodies, or any personal conflicts by the authors of the trial publication in any of the included trials.

\section{Effects of interventions}

See: Summary of findings for the main comparison Nonsteroid anti-inflammatory drugs versus placebo for biliary colic; Summary of findings 2 Non-steroid anti-inflammatory drugs versus opioids for biliary colic; Summary of findings $\mathbf{3}$ Non-steroid anti-inflammatory drugs versus spasmolytic drugs for biliary colic

\section{Primary outcomes}

\section{Mortality}

No participants in the included trials died.

\section{Lack of pain relief}

The definition of 'lack of pain relief' differed slightly in the included studies. However, it included:

- the need for a rescue therapy after a given period (15 minutes, 30 minutes, 1 hour, 24 hours, etc.) following NSAIDs administration;

- inadequately subjective pain relief within a given period following NSAIDs administration.

\section{NSAIDs versus placebo}

When compared with placebo, NSAIDs obtained a significantly lower proportion of participants without complete pain relief (risk ratio (RR) $0.27,95 \%$ confidence interval $(\mathrm{Cl}) 0.19$ to $0.40 ; \mathrm{I}^{2}=0 \%$ ) (Analysis 1.1).

Trial Sequential Analysis found that the required information size was 266 participants (see details in Figure 4). The cumulative number of participants enrolled in the trials included in this metaanalysis was 208 , corresponding to $78 \%$ of the information size. The results of the Trial Sequential Analysis support the finding that 
NSAIDs are superior to placebo in relieving pain, as the cumulative Z-curve crossed both the conventional and the trial sequential monitoring boundary for benefit (during the third trial in 1985)
(Figure 4). The Trial Sequential Analysis-adjusted $\mathrm{Cl}$ was 0.17 to 0.43 .

Figure 4. TSA - Lack of pain relief - NSAIDs versus placebo.

Trial Sequential Analysis was performed based on lack of complete pain relief occurrence of $\mathbf{7 8 . 4 \%}$ in the placebo group; a relative risk reduction of $20 \%$; a risk of type I error of $5 \%$; and a power of $80 \%$. There was no diversity adjustment $\left(D^{2}=0\right)$. The resulting information size was 266 . The blue line represents the cumulative Z-score of the meta-analysis. The green-dashed lines represent the conventional ( $\alpha=5 \%$ ) boundaries for statistical significance. The two red-dashed inward-sloping lines represent the trial sequential monitoring boundaries. The two red-dashed outward-sloping lines represent the futility boundaries.

Required information size is a Two-sided graph

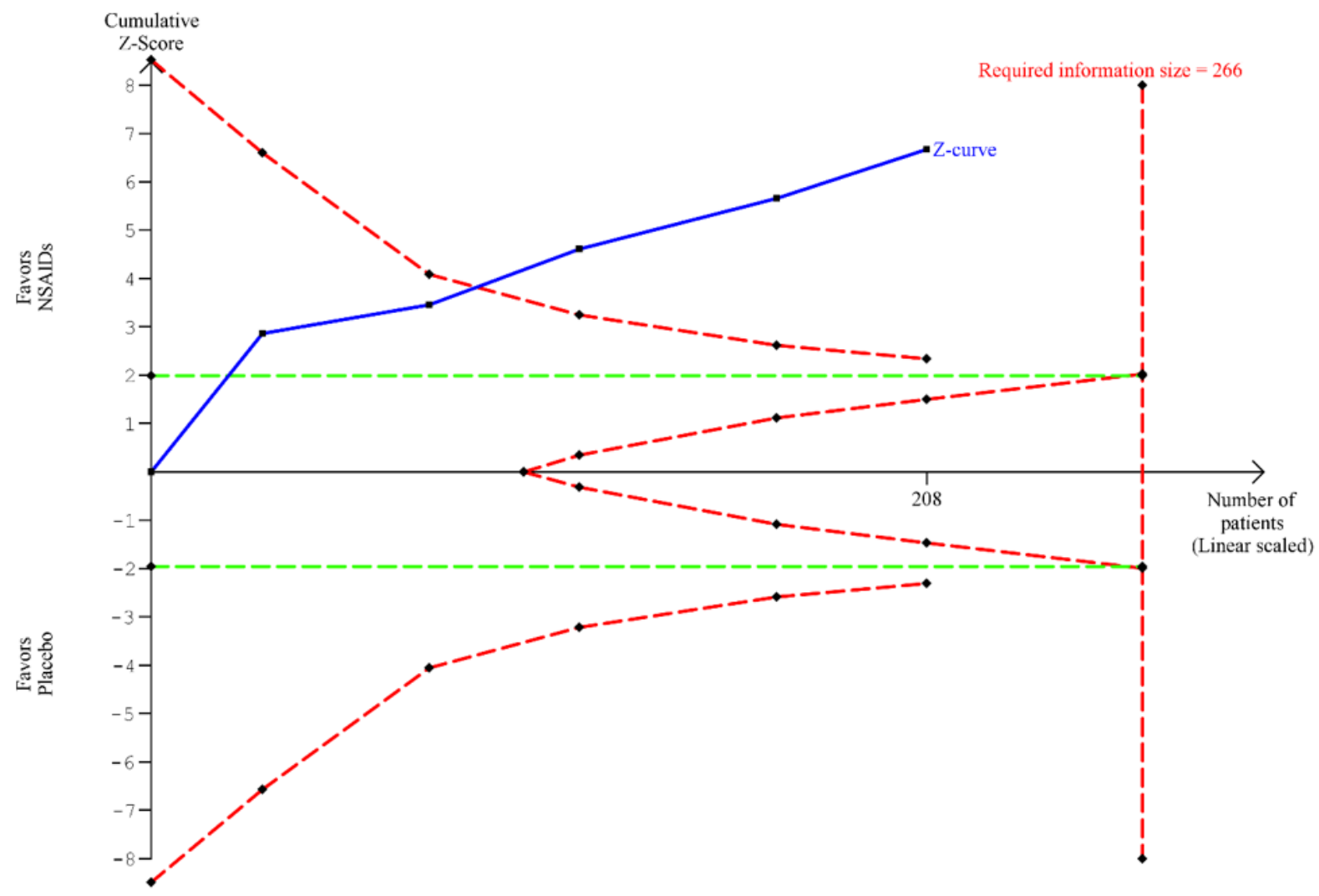

\section{NSAIDs versus opioids}

We found no difference when comparing NSAIDs to opioids (different doses) (ketorolac, three trials (Dula 2001; Henderson 2002; Olsen 2008); flurbiprofen, one trial (Camp 1992)) (RR 0.98, $95 \% \mathrm{Cl} 0.47$ to $2.07 ;\left.\right|^{2}=52 \%$ ) (Analysis 2.1 ).

Trial Sequential Analysis was performed considering an event rate in the control group of $18 \%$, a relative risk reduction of $20 \%$, risk of type I error of $5 \%$, power of $80 \%$, and diversity $88 \%$. The required information size was 13,657 participants. The number of participants included in this meta-analysis was 459 , corresponding to $3.4 \%$ of the information size. We did not calculate the Trial Sequential Analysis-adjusted $\mathrm{Cl}$ due to little information (3.4\%).

\section{NSAIDs versus spasmolytic drugs}

When compared with spasmolytic drugs, NSAIDs (diclofenac, two trials (Grossi 1986; Kumar 2004); tenoxicam, one trial (Al Waili 1998); and flurbiprofen, one trial (Camp 1992)) showed a significantly lower proportion of participants without complete pain relief (RR $0.51,95 \% \mathrm{Cl} 0.37$ to $0.71 ; 1^{2}=0 \%$ ) (Analysis 3.1 ).

Trial Sequential Analysis found that the required information size was 626 participants (see details in Figure 5). The total number of participants included in this analysis was 190 (30\% of the information size). The results of the Trial Sequential Analysis do not support the finding that NSAIDs are superior to spasmolytic drugs in relieving pain, as the cumulative Z-curve did not cross the trial sequential boundaries (Figure 5). The Trial Sequential Analysisadjusted $\mathrm{Cl}$ was 0.27 to 0.98 . 
Figure 5. TSA - Lack of pain relief - NSAIDs versus spasmolytic drugs. Trial Sequential Analysis was performed based on lack of complete pain relief occurrence of $56 \%$ in the spasmolytic drugs group; a relative risk reduction of $\mathbf{2 0 \%}$; a risk of type I error of $5 \%$; and a power of $80 \%$. There was no diversity adjustment $\left(D^{2}=0\right)$. The resulting information size was 626 . The blue line represents the cumulative Z-score of the meta-analysis. The green-dashed lines represent the conventional $(\alpha=5 \%)$ boundaries for statistical significance. The two red-dashed inward-sloping lines represent the trial sequential monitoring boundaries.

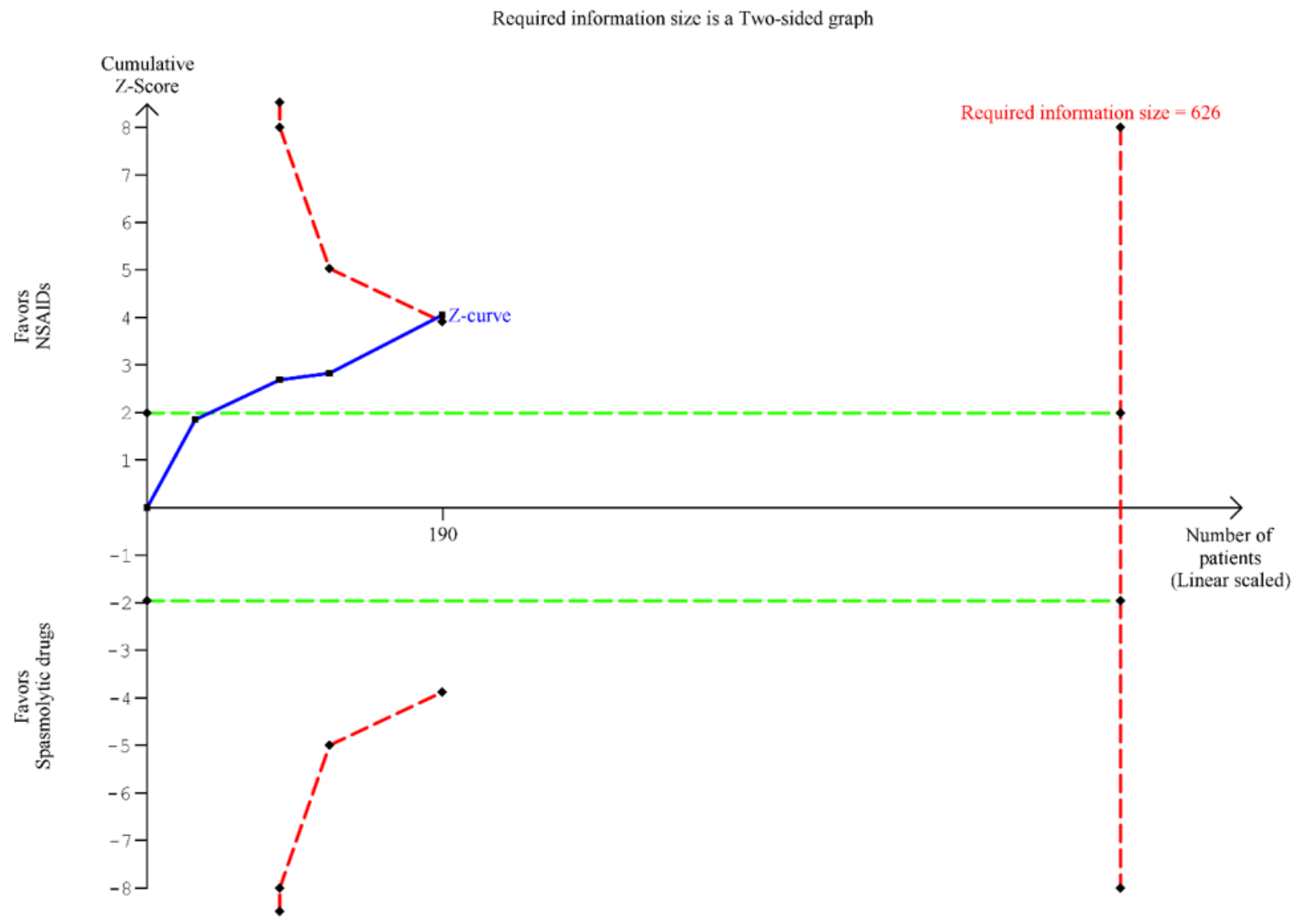

\section{Secondary outcomes}

\section{Cholelithiasis-related complications}

NSAIDs versus placebo

Three trials reported data on cholelithiasis-related complications (Lundstam 1985; Akriviadis 1997; Goldman 2001). When compared with placebo, NSAIDs showed no effect on complications (RR 0.66 , $95 \% \mathrm{Cl} 0.38$ to $1.15 ; \mathrm{I}^{2}=26 \%$ ) (Analysis 1.2 ).
Trial Sequential Analysis showed that the required information size was 1788 participants (see details in Figure 6). The cumulative number of participants enrolled in the trials included in this metaanalysis was 140 , corresponding to $8 \%$ of the information size. The cumulative Z-curve did not cross the trial sequential monitoring boundaries. The Trial Sequential Analysis-adjusted $\mathrm{Cl}$ was 0.07 to 6.19 . 
Figure 6. TSA - Cholelithiasis-related complications - NSAIDs versus placebo. Trial Sequential Analysis was performed based on cholelithiasis-related complications occurrence of $47 \%$ in the placebo group; a relative risk reduction of $20 \%$; a risk of type I error of $5 \%$; and a power of $80 \%$; heterogeneity adjustment based on $D^{2}=50 \%$. The resulting information size was 1788 . The blue line represents the cumulative Z-score of the meta-analysis. The green-dashed lines represent the conventional $(\alpha=5 \%)$ boundaries for statistical significance. The two pieces of red inward-sloping lines represent the trial sequential monitoring boundaries.

Alpha spending is a Two-sided graph

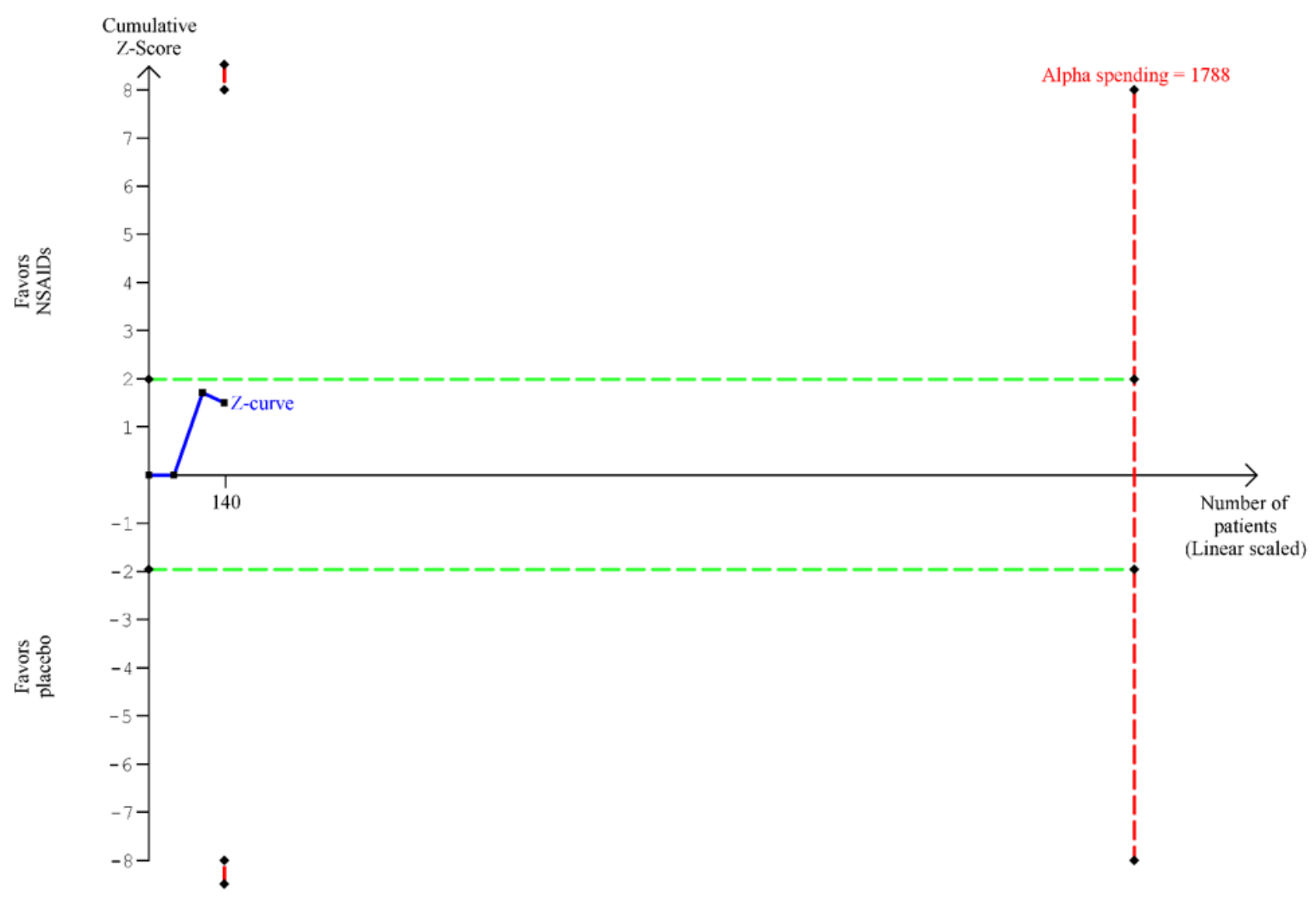

\section{NSAIDs versus opioids}

Only one trial comparing NSAIDs with opioids reported data on cholelithiasis-related complications (Dula 2001), and found no difference in the occurrence of events between the two groups (Analysis 2.2).

As only one trial was included, we did not perform the Trial Sequential Analysis. However, we attempted to estimate the required information size (assuming a rate of events in the control group of $14 \%$, a relative risk reduction of $20 \%$, a risk of type I error of $5 \%$, a power of $80 \%$, and a diversity of $50 \%$ ), which resulted in 8820 participants. We did not calculate the Trial Sequential Analysisadjusted $\mathrm{Cl}$ due to little information (0.3\%).

\section{NSAIDs versus spasmolytic drugs}

Two trials reported data on cholelithiasis-related complications (Al Waili 1998; Kumar 2004). When compared with spasmolytics, NSAIDs showed a significantly lower proportion of disease-related complications ( $\mathrm{RR} 0.27,95 \% \mathrm{Cl} 0.12$ to $0.57 ; \mathrm{I}^{2}=0 \%$ ) (Analysis 3.2 ).

Trial Sequential Analysis showed that the required information size was 1800 participants (see details in Figure 7). The cumulative number of participants enrolled in the trials included in this metaanalysis was 104 , corresponding to $6 \%$ of the information size. The results of the Trial Sequential Analysis do not support the finding of the conventional meta-analysis. The cumulative Z-curve did not cross the trial sequential monitoring boundaries (Figure 7). The Trial Sequential Analysis-adjusted Cl was 0.01 to 6.06 . 
Figure 7. TSA - Cholelithiasis-related complications - NSAIDs versus spasmolytic drugs. Trial Sequential Analysis was performed based on cholelithiasis-related complications occurrence of $46 \%$ in the placebo group; a relative risk reduction of $\mathbf{2 0 \%}$; a risk of type I error of $\mathbf{5 \%}$; and a power of $\mathbf{8 0} \%$. As only two studies were included, we used a more conservative heterogeneity adjustment based on $D^{2}=50 \%$ rather than data-based diversity $\left(D^{2}\right.$ was 0$)$. The resulting information size was $\mathbf{1 8 0 0}$. The blue line represents the cumulative Z-score of the meta-analysis. The green-dashed lines represent the conventional $(\alpha=5 \%)$ boundaries for statistical significance. The two pieces of red inward-sloping lines represent the trial sequential monitoring boundaries.

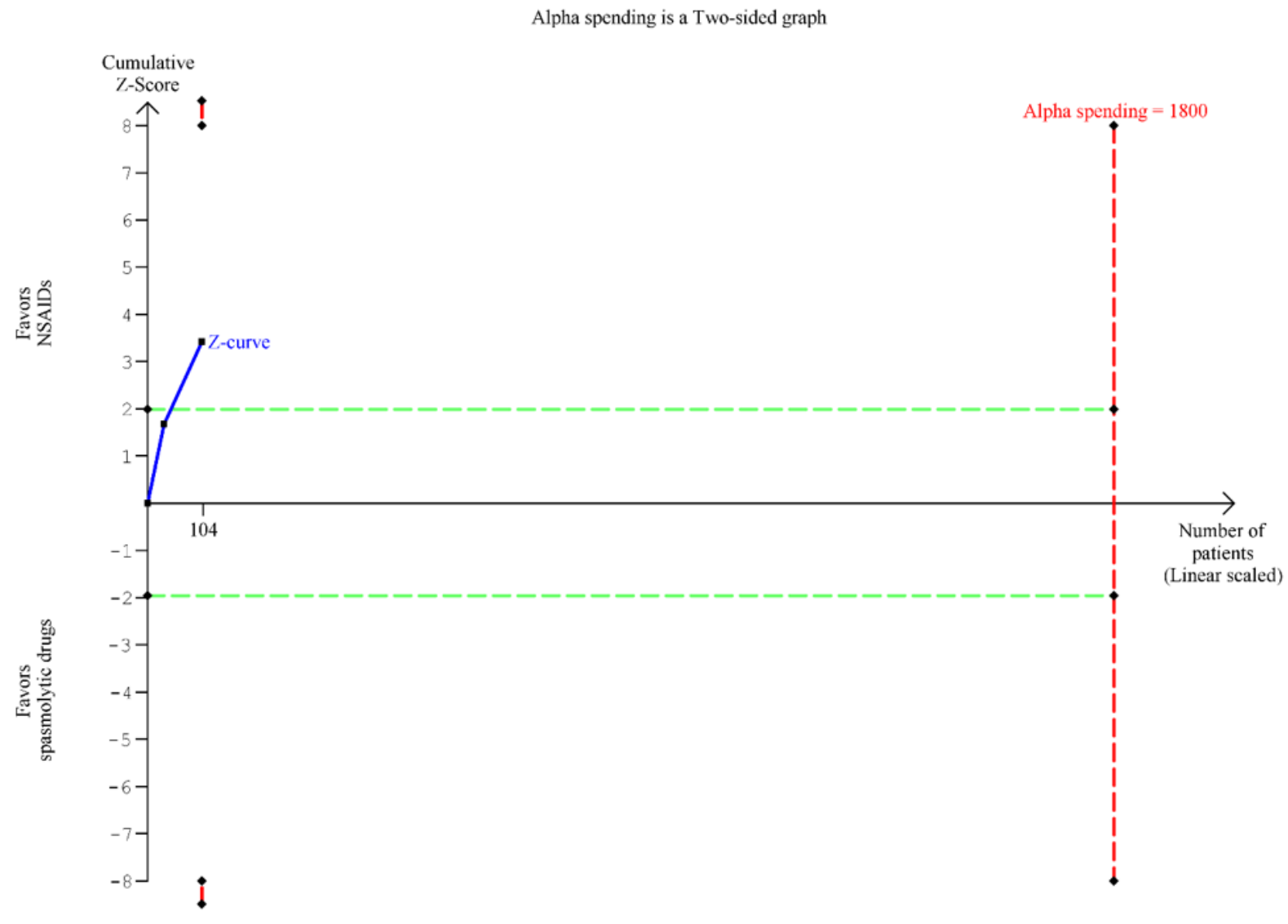

No data were available from the trial reports concerning either the risk of bleeding after an operative intervention or after an ERCP procedure.

Major bleeding was defined as a reduction in the haemoglobin level of at least 20 grams per litre, transfusion of at least 2 units of blood, or symptomatic bleeding.

Life-threatening bleeding was a subcategory of major bleeding that consisted of fatal bleeding, symptomatic intracranial bleeding, bleeding with a decrease in the haemoglobin level of at least 50 grams per litre, or bleeding requiring transfusion of at least 4 units of blood or inotropic agents or necessitating surgery.

\section{Quality of life}

None of the included trials assessed quality of life.

\section{Drug-related complications and adverse events, expressed as the number of participants experiencing these events}

None of the 12 included trials reported severe adverse events. Seven out of the 12 trials assessed non-severe adverse events; in two out of the seven trials no adverse events were observed. In the trial by Camp and colleagues (Camp 1992), some mild adverse events were reported. Among the 30 participants on flurbiprofen, one participant had fever and one experienced anxiety; among the 25 participants on hyoscine butylbromide one had headache, one nausea, one dry mouth, and one tachycardia; and among the 29 participants on pentazocine, six had nausea, four vomiting, one dry mouth, and five dizziness. In the trial by Grossi and colleagues (Grossi 1986), no participants on diclofenac or hyoscine butylbromide experienced adverse events. However, diclofenac and hyoscine butylbromide caused a significant decrease in systolic blood pressure. In the trial by Henderson and colleagues (Henderson 2002), drowsiness was the most frequent adverse event, observed in $34.6 \%$ of the 175 participants treated with ketorolac and $42.1 \%$ of the 149 participants treated with pethidine. Nausea and dizziness were significantly more frequent in the pethidine group than in the ketorolac group ( $16.4 \%$ versus $6.8 \%$ and $17.9 \%$ versus $6.8 \%$ ). In the trial by Olsen and colleagues (Olsen 2008), the proportion of participants experiencing nausea ( $24 \%$ versus $4 \%)$, vomiting $(5 \%$ versus $0 \%)$, and rash $(0 \%$ versus $4 \%$ ) did not differ significantly between the ketorolac 
group and the butorphanol group, whereas the proportion of participants experiencing sedation (5\% versus $36 \%$ ) and dizziness ( $0 \%$ versus $28 \%$ ) was significantly higher in the butorphanol group as compared to ketorolac group. In the trial by Lunstam and colleagues (Lundstam 1985), only significant decrease in systolic blood pressure was observed in both groups (diclofenac or placebo). In the trial by Magrini and colleagues (Magrini 1985), blood pressure was moderately but significantly decreased in the two treatment groups (ketoprofen or lysine acetyl salicylate), while this was not observed in the placebo group.

Meta-analyses of the quantification of pain relief were not possible as the included trials used different scoring scales, and pain was assessed at different time points after the intervention. Also, the definition of the timespan to obtain pain relief was very heterogeneous among trials, preventing any possible comparison among patient groups.

\section{Quantification of pain relief}

In most of the included trials quantification of pain relief was assessed using different visual analogue scales (VAS), precluding any possible comparisons among trial participant groups.

Broggini 1984 assessed the severity of pain used a three-point scale $(1=$ no relief, $2=$ partial relief, $3=$ complete relief) every 5 minutes up to 25 minutes after drug injection. Lundstam 1985 used a similar approach, assessing pain intensity after 15 and 30 minutes after the drug injection. Dula 2001 rated pain severity according to a four-point scale $(0=$ no effective, $1=$ mildly effective, 2 = moderately effective, $3=$ completely effective) before and 30 minutes after injection of medication. In Henderson 2002, pain severity was graded on a four-point categorical scale $(0=$ no pain, $1=$ mild, 2 = moderate, $3=$ severe), and mean VAS for the two treatment groups were compared after 30 minutes, 1 and 2 hours after drug injection. Camp 1992 used a four-point semi-quantitative scale to quantify pain severity $(0=$ no pain, $1=$ mild, $2=$ moderate 3 = severe), and the evolution of pain was checked every hour until 6 hours after drug injection. Magrini 1985 used a five-point scale ( $0=$ no pain, $1=$ mild, $2=$ moderate, $3=$ severe $4=$ very severe $)$, but pain intensity was assessed at $15,30,60$, and 120 minutes after drug injection. In Akriviadis 1997, response of pain to treatment was defined as no response (same or worse grade), improvement (amelioration of pain by at least one grade), or relief. The severity of pain was graded according to a four-point scale $(0=$ absent, $1=$ mild, 2 = moderate, and 3 = severe requiring analgesia). Sequential assessment for response of pain to treatment was performed every 15 minutes for the first 120 minutes and every 60 minutes for the first 8 hours after drug administration. In Al Waili 1998, a five-point categorical scale $(0=$ no pain, $1=$ mild, $2=$ moderate, $3=$ severe, $4=$ very severe) was used and mean VAS recorded at 30 and 60 minutes after drug administration. In Kumar 2004, pain severity was recorded on a 10-point VAS and checked at 30 minutes, 1, 2, and 4 hours after drug injection. Olsen 2008 used a 10-point faces numerical pain scale (1 minimal pain, 10 maximal) and assessed pain intensity 15 and 30 minutes after drug administration. In Goldman 2001, the severity of pain was rated on an A-to-D scale ( $A=$ mild pain; $D$ = intractable pain) every 10 to 15 minutes. Grossi 1986 assessed the intensity of pain at 30 and 60 minutes after medication injection using a 100-millimetre analogue chromatic scale $(0 \mathrm{~mm}=$ no pain, $100 \mathrm{~mm}$ = unbearable pain). Differences in the scales used for rating pain were accounted for by multiplying by 10 for the 10 point scale, by 20 for the five-point scale, and by 25 for the four- point scale. We left unchanged scales in which pain was rated on a 100-millimetre analogue chromatic rating system (data synthesis or extraction).

In Broggini 1984, mean pain intensity changed 25 minutes after the injection on the VAS, from $80 \mathrm{~mm}$ to $9 \mathrm{~mm}$ in the diclofenac group and from $85 \mathrm{~mm}$ to $86 \mathrm{~mm}$ in the placebo group.

Lundstam 1985 observed that pain estimated on the VAS was reduced by $58 \%$ in the diclofenac group and 39\% in the placebo group.

Dula 2001 observed that pain relief at 30 minutes was $3.8 \pm 2.6$ in the ketorolac group and $3.9 \pm 2.5$ in the pethidine group, a difference that was not statistically significant.

In Henderson 2002, no significant differences in mean VAS values were found between groups at two hours after drug injection (ketorolac versus pethidine).

In Camp 1992, participants receiving ibuprofen showed significantly lower mean pain intensity VAS values compared to those receiving pentazocine or hyoscine butylbromide.

In Magrini 1985, total pain score and VAS values were significantly lower at each time point in the ketoprofen group as compared to placebo.

In Akriviadis 1997, response of pain to treatment was defined as no response (same or worse grade), improvement (amelioration of pain by at least one grade), or relief. No data were available regarding pain quantification and its modification over time (Akriviadis 1997).

In Al Waili 1998, mean pain score in the tenoxicam group decreased from $2.75 \pm 0.9$ to $0.49 \pm 0.51$ at 30 minutes and to $0.58 \pm 0.57$ at 60 minutes; in the hyoscine butylbromide group pain decreased from $2.62 \pm 1.0$ to $0.57 \pm 0.5$ at 30 minutes and to $0.66 \pm 0.5$ at 60 minutes.

In Kumar 2004, at 2 hours from injection, pain severity in the diclofenac group decreased from $9.5 \pm 0.54$ to $0.62 \pm 0.83$, and in the hyoscine group it decreased from $9.6 \pm 0.48$ to $1.69 \pm 1.0$.

In Goldman 2001, severity of pain was rated on an A-to-D scale (A $=$ mild pain; $\mathrm{D}=$ intractable pain) every 10 to 15 minutes. No data were available on the quantification of pain, but average response time lapse was shortest in the diclofenac group (15 minutes) as compared to placebo ( 35 minutes) and papaverine group (20 minutes).

Grossi 1986 observed the course of pain intensity over the 60 minutes after injection, showing that all three of the drugs studied were effective in relieving pain, however the diclofenac group showed a significantly higher reduction in mean pain score as compared to the glucagon and hyoscine butylbromide groups.

\section{The time needed to obtain pain relief}

Most of the included trials reported the time needed to obtain pain relief only as a descriptive variable. Most of the trials assessed participants at predefined time intervals, ranging from 25 minutes up to 3 hours (see data reported in the Methods section and in the previous paragraph). 


\section{Subgroup analyses}

It was not possible to conduct any of the planned subgroup analyses due to the low number of trials and the lack of data regarding the predefined variables.

\section{Sensitivity analysis}

We planned no sensitivity analysis.

\section{Adverse events reported in non-randomised studies}

Our search was primarily aimed at identifying randomised clinical trials. However, we retrieved from the searches several citations from quasi- or non-randomised studies. We searched for adverse events in these studies, but were unable to find any specific adverse events.

\section{Publication bias}

It was not possible to create a funnel plot to assess publication bias as the number of trials in each of the four meta-analyses was less than 10.

\section{GRADE assessments}

We rated the quality of evidence for two of the primary outcomes, lack of pain relief and cholelithiasis-related complications, in the 'Summary of findings' tables. We performed the assessment of these outcomes for the three analysed comparisons in separate: NSAIDs versus placebo; NSAIDs versus opioids; and NSAIDs versus spasmolytic drugs. For the comparison NSAIDs versus placebo, we graded the overall quality low for 'lack of pain relief' and very low for 'cholelithiasis-related complications' (Summary of findings for the main comparison); for NSAIDs versus opioids, we graded the overall quality very low for both 'lack of pain relief' and 'cholelithiasis-related complications' (Summary of findings 2); and for NSAIDs versus spasmolytic drugs, we graded the overall quality low for both 'lack of pain relief' and 'cholelithiasis-related complications' (Summary of findings 3 ).

\section{DISCUSSION}

\section{Summary of main results}

Twelve randomised clinical trials assessed the use of NSAIDs in people attending emergency departments with symptoms of biliary colic. Our traditional meta-analysis showed NSAIDs to be effective in relieving pain by significantly reducing the number of participants without complete pain relief in comparison to placebo or spasmolytic drugs. However, Trial Sequential Analysis confirmed only the result obtained when comparing NSAIDs with placebo. The trials comparing NSAIDs and opioids failed to demonstrate a significant difference; however, present data are not able to definitively support equivalence in pain relief between these two classes of drugs. Moreover, NSAIDs significantly reduced the proportion of short-term complications such as acute cholecystitis, jaundice, cholangitis, and acute pancreatitis when compared with spasmolytics, but not when compared with placebo. This effect may be due either to a beneficial effect of NSAIDs or to a harmful effect of spasmolytic drugs, however the latter could not be currently determined.

Five trials tested diclofenac $50 \mathrm{mg}$ to $75 \mathrm{mg}$ intramuscularly (i.m.) and ketoprofen $200 \mathrm{mg}$ intravenously (i.v.) against placebo (saline) with consistent results demonstrating a superior analgesic efficacy of these two NSAIDs. This result was confirmed by the Trial Sequential Analysis. However, the comparison between NSAIDs and other commonly used drugs (spasmolytic and opioid) seems more relevant.

Hyoscine butylbromide (also known as scopolamine) is an anticholinergic drug, commonly used because of its presumed spasmolytic activity. We found four randomised clinical trials comparing NSAIDs and hyoscine butylbromide that consistently and significantly demonstrated a more effective pain relief with NSAIDs (diclofenac $75 \mathrm{mg}$ i.m., tenoxicam $20 \mathrm{mg}$ i.v., and flurbiprofen $150 \mathrm{mg}$ i.m.) than the spasmolytic drugs (hyoscine butylbromide $20 \mathrm{mg}$ i.v. or i.m., hyoscine butylbromide $20 \mathrm{mg}$ i.m). In one trial, glucagon (1 mg i.m.) was as effective as diclofenac (75 mg i.m) for obtaining pain relief (Grossi 1986). However, glucagon is no longer used due to its adverse effects. Due to their wellknown analgesic effect, pethidine and pentazocine are commonly used, in particular because they prevent the sphincter of Oddi spasm associated with use of the other opioids. However, the Trial Sequential Analysis did not support the finding of the conventional meta-analysis, suggesting that firm evidence has not yet been reached.

Only four trials compared NSAIDs versus opioids (two with pethidine, one with pentazocine, and one with butorphanol) including about 242 and 217 participants in each group. The results for this comparison showed significant statistical heterogeneity, and no difference in the analgesic effect was observed between the two drugs. A possible explanation for the inconsistency of data could be related to the different drugs used, route of administration, and time of pain assessment. In particular, the largest trial by Henderson (Henderson 2002) used pethidine $50 \mathrm{mg}$ intravenously and assessed pain after 1 hour, whereas the other three smaller trials used pentazocine or pethidine intramuscularly and assessed pain earlier, at 30 minutes. The present data do not allow us to reject the null hypothesis, as they are underpowered. Also in this analysis, the Trial Sequential Analysis did not support the result of the meta-analysis, implying that firm evidence was not reached.

The percentage of participants with biliary colic who developed cholelithiasis-related complications such as cholecystitis, or less frequently choledocholithiasis, cholangitis, or gallstone pancreatitis, varied. Our results indicate that NSAIDs were not able to reduce the rate of short-term complications of biliary colic in comparison with placebo; we observed a reduction in the rate of cholelithiasis-related complications in comparison with spasmolytic drugs, even if this result was not confirmed by Trial Sequential Analysis.

The interpretation of our findings regarding cholelithiasis-related complications is difficult and should be considered with caution. In fact, the studies included in the two analyses (NSAIDs versus placebo and NSAIDs versus spasmolytic drugs) are very different. For example, there was a higher rate of complications in the treatment arm of trials included in the former analysis (29\%) as compared to the latter analysis (11\%). This is likely a consequence of different participant selection with varying disease severity and probably for different definitions of complications. In only one trial, comparing NSAIDs versus placebo, were cholelithiasisrelated complications assessed and separately reported according to clearly predefined criteria (Akriviadis 1997). In two other trials, comparing NSAIDs versus placebo (Lundstam 1985; Goldman 
2001), and in two trials comparing NSAIDs versus spasmolytics (Al Waili 1998; Kumar 2004), only the rate of clinically evident cholecystitis was recorded. In addition, when exclusion criteria were stricter in some of the trials (Al Waili 1998; Dula 2001), incidences of complications were lower. People with diabetes or other systemic comorbidities and people older than 65 years were excluded from all trials, apart from Akriviadis 1997. These people can be regarded as a subgroup in which complications related to cholelithiasis are more frequent and severe (Kimura 2007).

The above concept applies also for adverse events related to NSAIDs. In most of the included trials, data collection about adverse drug effects was neither planned nor reported. These limitations prevent clear and definitive assessment of the benefits and harms of the use of NSAIDs just in the subgroup of participants with higher risk of severe complications, particularly in comparison to pethidine, which shows at least similar analgesic activity (Dula 2001; Henderson 2002).

There was no clear difference in the reported number or severity of adverse effects between the different types of NSAIDs in the trials included in this review. Several articles have reported on the adverse effects of NSAIDs, especially gastrointestinal events. Adverse effects that were more frequently reported in the trials presented in this review included nausea, dry mouth, abdominal pain, diarrhoea, oedema, decrease in systolic blood pressure, rash, dizziness, headache, tiredness, fever, and anxiety.

The authors of the included trials considered most adverse effects to be mild to moderate. However, as the sample sizes of most of the studies were relatively small, no clear conclusion can be drawn regarding the risks for gastrointestinal and other adverse effects of NSAIDs.

Regarding the possible onset of cardiovascular adverse effects, apart from a transitory decrease in systolic blood pressure, these were not reported in the trials included in our present review. However, it must be noted that cardiovascular adverse events are more common with the use of cyclooxygenase-2 (COX-2) inhibitor drugs than with classical NSAIDs, and that the use of NSAIDs can be considered to be relatively safe when prescribed at the most effective dose and for the shortest period of time (Aminoshariae 2016). Indeed, in the trials included in the present systematic review, NSAIDs were used for a very short period of time, and in all cases for less than 10 days.

None of the included trials reported data on the possible association between NSAIDs use and increased risk of bleeding after surgical or endoscopic procedures for cholelithiasis-related complications. In a recent meta-analysis of rectal NSAIDs in the prevention of post-ERCP pancreatitis, the risk of bleeding seems not to be increased (Elmunzer 2008). Interestingly, NSAIDs are effective in the prevention of post-ERCP pancreatitis, and this may further support our findings of a low proportion of cholelithiasis-related complications, probably related to inhibition of prostaglandin, phospholipase A2, and neutrophil-endothelial interactions, all of which are involved in their pathogenesis (Zheng 2008).

We also found one ongoing randomised clinical trial that aims to assess the analgesic efficacy of intravenous ibuprofen in biliary colic.

\section{Overall completeness and applicability of evidence}

This systematic review examined the evidence from 12 randomised trials comparing NSAIDs versus no intervention, placebo, or other drugs in people attending emergency departments with symptoms of biliary colic. These trials included all people presenting with biliary colic according to the definitions and diagnostic work-up in the individual trials.

All trials reported on the primary outcomes of mortality, (lack of) complete pain relief, and number of participants with cholelithiasis-related complications, whereas in most of the included trials no data were available regarding drug-related complications and adverse events, and most of the remaining secondary outcomes such as risk of bleeding after surgical or endoscopic procedures, quality of life, quantification of pain relief, and time to obtain pain relief.

In addition, when exclusion criteria were stricter in some of the trials (Al Waili 1998; Dula 2001), incidences of complications were lower. People with diabetes or other systemic comorbidities or who were older than 65 years were excluded from all trials, apart from Akriviadis 1997. These people can be regarded as a subgroup in which complications related to cholelithiasis are more frequent and severe (Kimura 2007).

\section{Quality of the evidence}

We conducted our review following the recommendations of the Cochrane Handbook for Systematic Reviews of Interventions and the Cochrane Hepato-Biliary Group (Higgins 2011; Gluud 2016). The findings of our review and the quality of the evidence are affected by the quality of the primary trials included in the review. We found only one trial to be at low risk of bias for all the quality domains considered. We considered most of the trials to be at unclear risk of bias for at least two quality domains, and only one trial to be at high risk of bias for at least one quality domain. In particular, we more frequently observed risk of bias for the random sequence generation and allocation concealment domains, both of which reflect the presence of a selection bias.

However, for trials classified as at unclear risk of bias, we cannot exclude the presence of high risk of bias.

We also performed Trial Sequential Analysis to deal with the risks of random errors and to prevent premature declaration of superiority of NSAIDs (Wetterslev 2009). According to these analyses, systematic errors may still influence the results of a number of comparisons in our review.

Regarding GRADE assessments, we rated none of the trials as providing strong evidence, primarily because of the presence of risk of bias, the required information size was not reached, and imprecision of pooled estimates.

Overall, we did not observe relevant heterogeneity among the studies apart from exclusion criteria differing in some of them, for example the exclusion of participants older than 65 years or of those with comorbidities such as diabetes, or a different definition of complications.

The presence of a possible publication bias cannot be excluded as a formal analysis was prevented by the small number of studies. 


\section{Potential biases in the review process}

We attempted to minimise the risk of bias in the review process by strictly following Cochrane's methodology during the preparation of our review.

We performed an exhaustive bibliographic search, and two review authors extracted data independently. Although the search strategy was very sensitive, due to the low number of included trials we could not test for funnel plot asymmetry to assess the risk of publication bias. This is a clear limitation of our review.

The quality of the primary trials included in our review is, as usual, a limiting factor for the strength of the evidence of our results.

\section{Agreements and disagreements with other studies or reviews}

With respect to the two non-Cochrane systematic reviews already published (Basurto Ona 2008; Colli 2012), some main differences should be underlined.

The earliest-dated review is a Spanish review that does not compare NSAIDs versus placebo or other drugs for biliary colic in people with cholelithiasis (Basurto Ona 2008). The authors concluded that NSAIDs are the first drugs that should be used in people with uncomplicated biliary colic, as they found a significantly higher analgesic effect and a better prognosis (lower rate of progression to acute cholecystitis) for NSAIDs as compared to 'other drugs', which, differing from the present review, they considered to be a heterogeneous group of drugs. Basurto Ona 2008 included only seven randomised clinical trials that enrolled 349 participants (Niinikoski 1984; Grossi 1986; Camp 1992; Al Waili 1998; Dula 2001; Goldman 2001; Kumar 2004). We included all of these studies, apart from one that we excluded as it compares two NSAIDs (indomethacin $50 \mathrm{mg}$ versus metamizole $2.5 \mathrm{~g}$ ) (Niinikoski 1984), in our own review.

Our own group published the other non-Cochrane review (Colli 2012). In this review, we did not rate the overall evidence and did not perform a Trial Sequential Analysis to calculate the cumulative sample size of the meta-analysis (information size), thus overestimating the efficacy of NSAIDs in reducing biliary colic complications.

\section{AUTHORS' CONCLUSIONS}

\section{Implications for practice}

Our results indicate that NSAIDs control pain better than placebo and spasmolytic drugs in people with biliary colic. However, only one randomised clinical trial was at low risk of bias.
We found limited evidence that NSAIDs reduce cholelithiasisrelated complications. Regarding the reduced risk of cholelithiasisrelated complications observed for NSAIDs versus spasmolytic drugs, the evidence is provided by only two trials including 104 participants. In addition, it is unclear whether this finding is related to the beneficial effect of NSAIDs or to a harmful effect of spasmolytics.

Furthermore, regarding the presence of complications, a limitation of the present systematic review is that its generalisability is low as most of the randomised clinical trials did not include elderly people or people with co-morbidities, or both, who are more prone to complication as compared to other included participants.

None of the trials provided information on quality of life, and information on adverse events remains unclear.

\section{Implications for research}

We need more evidence with appropriately sized randomised clinical trials at low risk of bias before we can draw any firm conclusions on the effect of NSAIDs in pain control for people with biliary colic.

The lack of data regarding people with a wider spectrum of age or with co-morbidities (e.g. diabetes, etc.), or both, actually representing the subgroup with a higher proportion of severe gallstone-related complications, makes the conclusions of this review not completely generalisable, indicating a need for new trials with less stringent inclusion criteria.

\section{ACKNOWLEDGEMENTS}

We are indebted to Sarah Klingenberg and Giovanna Pistotti for their precious help in revising the search strategy terms.

Peer reviewers: Jessica Vaughan, UK; Malgorzata Bala, Poland. Contact editors: Saboor A. Khan, UK; Frederik Keus, the Netherlands; Christian Gluud, Denmark.

Cochrane Review Group funding acknowledgement: the Danish State is the largest single funder of the Cochrane Hepato-Biliary Group through its investment in the Copenhagen Trial Unit, Centre for Clinical Intervention Research, Rigshospitalet, Copenhagen University Hospital, Denmark. Disclaimer: The views and opinions expressed in this review are those of the authors and do not necessarily reflect those of the Danish State or the Copenhagen Trial Unit. 


\section{RE F E R E N C E S}

\section{References to studies included in this review}

Akriviadis 1997 \{published data only\}

Akriviadis EA, Hatzigavriel M, Kapnias D, Kirimlidis J, Markantas A, Garyfallos A. Treatment of biliary colic with diclofenac: a randomized, double-blind, placebo-controlled study. Gastroenterology 1997;113:225-31.

\section{Al Waili 1998 \{published data only\}}

Al-Waili N, Saloom KY. The analgesic effect of intravenous tenoxicam in symptomatic treatment of biliary colic: a comparison with hyoscine N-butylbromide. European Journal of Medical Research 1998;3:475-9.

\section{Broggini 1984 \{published data only\}}

Broggini M, Corbetta E, Grossi E, Borghi C. Diclofenac sodium in biliary colic: a double blind trial. British Medical Journal (Clinical Research Ed.) 1984;288:1042.

\section{Camp 1992 \{published data only\}}

Camp Herrero J, Artigas Raventos V, Millà Santos J, Allende Honorato L, Dominguez Granados R, Moreno Carretero E. Efficacy of injectable flurbiprofen in the symptomatic treatment of biliary colic [Eficacia del flurbiprofeno inyectable en el tratamiento sintomatico del colico biliar]. Medicina Clinica 1992;98:212-4.

\section{Dula 2001 \{published data only\}}

Dula DJ, Anderson R, Wood GC. A prospective study comparing i.m. ketorolac with i.m. meperidine in the treatment of acute biliary colic. Journal of Emergency Medicine 2001;20(2):121-4.

\section{Goldman 2001 \{published data only\}}

Goldman G, Kahn PJ, Alon R, Wiznitzer T. Biliary colic treatment and acute cholecystitis prevention by prostaglandin inhibitor. Digestive Diseases and Sciences 1989;34(6):809-11.

\section{Grossi 1986 \{published data only\}}

Grossi E, Broggini M, Quaranta M, Balestrino E. Different pharmacological approaches to the treatment of acute biliary colic. Current Therapeutic Research, Clinical and Experimental 1986;40:876-82.

\section{Henderson 2002 \{published data only\}}

Henderson SO, Swadron S, Newton E. Comparison of intravenous ketorolac and meperidine in the treatment of biliary colic. Journal of Emergency Medicine 2002;23(3):237-41.

\section{Kumar 2004 \{published data only\}}

Kumar A, Deed JS, Bhasin B, Kumar A, Thomas S. Comparison of the effect of diclofenac with hyoscine-N-butylbromide in the symptomatic treatment of acute biliary colic. Australian and New Zealand Journal of Surgery 2004;371:435-9.

\section{Lundstam 1985 \{published data only\}}

Lundstam S, Ivarsson L, Lindblad L, Kral JG. Treatment of biliary pain by prostaglandin synthethase inhibition with diclofenac sodium. Current Therapeutic Research, Clinical and Experimental 1985;37:435-9.
Magrini 1985 \{published data only\}

* Magrini M, Rivolta G, Movilia PG, Moretti MP, Liverta C, Bruni G. Successful treatment of biliary colic with intravenous ketoprofen or lysine acetylsalicylate. Current Medical Research and Opinion 1985;9(7):454-60.

Olsen 2008 \{published data only\}

Olsen JC, McGrath NA, Schwarz DG, Cutcliffe BJ, Stern JL. A double-blind randomized clinical trial evaluating the analgesic efficacy of ketorolac versus butorphanol for patients with suspected biliary colic in the emergency department. Academic Emergency Medicine 2008;15:718-22.

\section{References to studies excluded from this review}

\section{Chang 2002 \{published data only\}}

Chang DJ, Desjardins PJ, Chen E, Polis AB, McAvoy M, Mockoviak $\mathrm{SH}$, et al. Comparison of the analgesic efficacy of rofecoxib and enteric-coated diclofenac sodium in the treatment of postoperative dental pain: a randomized, placebocontrolled clinical trial. Clinical Therapeutics 2002;24:490-503.

\section{Chaudhary 1999 \{published data only\}}

Chaudhary A, Gupta RL. Double blind, randomised, parallel, prospective, comparative, clinical evaluation of a combination of antispasmodic analgesic Diclofenac + Pitofenone + Fenpiverinium (Manyana) vs Analgin + Pitofenone + Fenpiverinium (Baralgan) in biliary, ureteric and intestinal colic. Journal of the Indian Medical Association 1999;97:244-5.

Kantor 1986 \{published data only\}

Kantor TG. Use of diclofenac in analgesia. American Journal of Medicine 1986;80:64-9.

\section{Marsala 1986 \{published data only\}}

Marsala F, Cavrini P, Bufalino L, Gardini F. Treatment of acute pain of ureteral and biliary colic with naproxen sodium administered by the parenteral route. International Journal of Clinical Pharmacology Research 1986;6:495-500.

Niinikoski 1984 \{published data only\}

Niinikoski J, Nelimarkka O, Pekkola P. Intravenous indomethacin in biliary pain. A clinical investigation with metamizole as the control. Annales Chirurgiae et Gynaecologiae 1984;73:69-72.

Thornell 1979 \{published data only\}

Thornell E, Jansson R, Kral JG, Svanvik J. Inhibition of prostaglandin synthesis as a treatment for biliary pain. Lancet 1979;1:584

\section{References to ongoing studies}

NCT02268955 \{unpublished data only\}

NCT02268955. Assessment of the analgesic efficacy of intravenous ibuprofen in biliary colic. clinicaltrials.gov/ct2/ show/NCT02268955 (accessed October 16, 2014). 


\section{Additional references}

\section{Aminoshariae 2016}

Aminoshariae A, Kulild JC, Donaldson M. Short-term use of nonsteroidal anti-inflammatory drugs and adverse effects: An updated systematic review. Journal of the American Dental Association (Edizione Italiana) 2016;147:98-110.

\section{Angelico 1997}

Angelico F, Del Ben M, Barbato A, Conti R, Urbinati G. Ten-year incidence and natural history of gallstone disease in a rural population of women in central Italy. The Rome group for the epidemiology and prevention of cholelitiasis (GREPCO). Italian Journal of Gastroenterology and Hepatology 1997;29:249-54.

\section{Attili 1995}

Attili AF, De Sanctis A, Capri R, Repice AM, Maselli S. The natural history of gallstones: the GREPCO experience. The GREPCO Group. Hepatology 1995;21(3):655-60.

\section{Balshem 2011}

Balshem H, Helfand M, Schunemann HJ, Oxman AD, Kunz R, Brozek J, et al. GRADE guidelines: 3 . Rating the quality of evidence. Journal of Clinical Epidemiology 2011;64(4):401-6. [PUBMED: 21208779]

\section{Basurto Ona 2008}

Basurto Ona X, Robles Perea L. Antinflammatory drugs for biliary colics: a systematic revision and meta-analysis of clinical trials [Antinflammatorios para el colico biliar: revision sistematica y metanalisis de ensayos clinicos]. Gastroenterologia y Hepatologia 2008;31:1-7.

\section{Brooks 1998}

Brooks P. Use and benefits of nonsteroidal anti-inflammatory drugs. American Journal of Medicine 1998;104:9S-13S.

\section{Colli 2012}

Colli A, Conte D, Della Valle S, Sciola V, Fraquelli M. Metaanalysis: nonsteroidal anti-inflammatory drugs in biliary colic. Alimentary Pharmacology \& Therapeutics 2012;35:1370-8.

\section{DeMets 1987}

DeMets DL. Methods for combining randomized clinical trials: strengths and limitations. Statistics in Medicine 1987;6(3):341-50.

\section{DerSimonian 1986}

DerSimonian R, Laird N. Meta-analysis in clinical trials. Controlled Clinical Trials 1986;7(3):177-88.

\section{Elmunzer 2008}

Elmunzer BJ, Waljee AK, Elta GH, Taylor JR, Fehmi SM, Higgins PD. A meta-analysis of rectal NSAIDs in the prevention of post-ERCP pancreatitis. Gut 2008;57:1262-7.

\section{Friedman 1993}

Friedman GD. Natural history of asymptomatic and symptomatic gallstones. American Journal of Surgery 1993;165:399-404.

\section{Gluud 2016}

Gluud C, Nikolova D, Klingenberg SL. Cochrane Hepato-Biliary Group. About Cochrane (Cochrane Review Groups (CRGs)) 2016, Issue 6. Art. No.: LIVER.

\section{Goldman 1989}

Goldman G, Kahn PJ, Alon R, Wiznitzer T. Biliary colic treatment and acute cholecystitis prevention by prostaglandin inhibitor. Digestive Diseases and Sciences 1989;34:809-11.

\section{Grepco I 1988}

The epidemiology of gallstone disease in Rome, Italy. Part I. Prevalence data in men. The Rome Group for Epidemiology and Prevention of Cholelithiasis (GREPCO). Hepatology (Baltimore, Md.) 1988;8:904-6.

\section{Grepco II 1988}

The epidemiology of gallstone disease in Rome, Italy. Part II. Factors associated with the disease. The Rome Group for Epidemiology and Prevention of Cholelithiasis (GREPCO). Hepatology (Baltimore, Md.) 1988;8:907-13.

\section{Guyatt 2008}

Guyatt G, Oxman AD, Vist GE, Kunz R, Falck Y, Alonso CP, et al. GRADE: an emerging consensus on rating quality of evidence and strength of recommendations. BMJ (Clinical Research Ed.) 2008;336(7650):924-6.

\section{Guyatt 2011}

Guyatt G, Oxman AD, Akl EA, Kunz R, Vist G, Brozek J, et al. GRADE guidelines: 1 . Introduction - GRADE evidence profiles and summary of findings tables. Journal of Clinical Epidemiology 2011;64(4):383-94. [PUBMED: 21195583]

\section{Guyatt 2011a}

Guyatt GH, Oxman AD, Kunz R, Atkins D, Brozek J, Vist G, et al. GRADE guidelines: 2. Framing the question and deciding on important outcomes. Journal of Clinical Epidemiology 2011;64(4):395-400. [PUBMED: 21194891]

\section{Guyatt 2011b}

Guyatt GH, Oxman AD, Vist G, Kunz R, Brozek J, Alonso-Coello P, et al. GRADE guidelines: 4 . Rating the quality of evidence study limitations (risk of bias). Journal of Clinical Epidemiology 2011;64(4):407-15. [PUBMED: 21247734]

\section{Guyatt 2011c}

Guyatt GH, Oxman AD, Montori V, Vist G, Kunz R, Brozek J, et al. GRADE guidelines: 5 . Rating the quality of evidence - publication bias. Journal of Clinical Epidemiology 2011;64(12):1277-82. [PUBMED: 21802904]

\section{Guyatt 2011d}

Guyatt GH, Oxman AD, Kunz R, Brozek J, Alonso-Coello P, Rind D, et al. GRADE guidelines 6 . Rating the quality of evidence - imprecision. Journal of Clinical Epidemiology 2011;64(12):1283-93. [PUBMED: 21839614]

\section{Guyatt 2011e}

Guyatt GH, Oxman AD, Kunz R, Woodcock J, Brozek J, Helfand M, et al. GRADE guidelines: 7 . Rating the quality of 
evidence - inconsistency. Journal of Clinical Epidemiology 2011;64(12):1294-302. [PUBMED: 21803546]

\section{Guyatt 2011 f}

Guyatt GH, Oxman AD, Kunz R, Woodcock J, Brozek J, Helfand M, et al. GRADE guidelines: 8 . Rating the quality of evidence - indirectness. Journal of Clinical Epidemiology 2011;64(12):1303-10. [PUBMED: 21802903]

\section{Guyatt 2011g}

Guyatt GH, Oxman AD, Sultan S, Glasziou P, Akl EA, AlonsoCoello P, et al. GRADE guidelines: 9. Rating up the quality of evidence. Journal of Clinical Epidemiology 2011;64(12):1311-6. [PUBMED: 21802902]

\section{Guyatt 2013}

Guyatt G, Oxman AD, Sultan S, Brozek J, Glasziou P, AlonsoCoello P, et al. GRADE guidelines: 11 . Making an overall rating of confidence in effect estimates for a single outcome and for all outcomes. Journal of Clinical Epidemiology 2013;66(2):151-7. [PUBMED: 22542023]

\section{Guyatt 2013a}

Guyatt GH, Oxman AD, Santesso N, Helfand M, Vist G, Kunz R, et al. GRADE guidelines: 12. Preparing summary of findings tables - binary outcomes. Journal of Clinical Epidemiology 2013;66(2):158-72. [PUBMED: 22609141]

\section{Guyatt 2013b}

Guyatt GH, Thorlund K, Oxman AD, Walter SD, Patrick D, Furukawa TA, et al. GRADE guidelines: 13. Preparing summary of findings tables and evidence profiles - continuous outcomes. Journal of Clinical Epidemiology 2013;66(2):173-83. [PUBMED: 23116689]

\section{Guyatt 2013c}

Guyatt G, Andrews J, Oxman AD, Alderson P, Dahm P, FalckYtter $Y$, et al. GRADE guidelines: 15. Going from evidence to recommendations: the significance and presentation of recommendations. Journal of Clinical Epidemiology 2013;66(7):719-25.

\section{Higgins 2011}

Higgins JPT, Green S (editors). Cochrane Handbook for Systematic Reviews of Interventions Version 5.1.0 [updated March 2011]. The Cochrane Collaboration, 2011. Available from handbook.cochrane.org.

\section{Jakobsen 2014}

Jakobsen J, Wetterslev J, Winkel P, Lange T, Gluud C. Thresholds for statistical and clinical significance in systematic reviews with meta-analytic methods. BMC Medical Research Methodology 2014;14:120.

\section{Johnson 2001}

Johnson CD. ABC of the upper gastrointestinal tract. Upper abdominal pain: gallbladder. BMJ (Clinical Research Ed.) 2001;323:316-20.

\section{Kimura 2007}

Kimura Y, Takada T, Kawarada Y, Nimura Y, Hirata K, Sekimoto M, et al. Definitions, pathophysiology, and epidemiology of acute cholangitis and cholecystitis: Tokyo Guidelines. Journal of Hepato-Biliary-Pancreatic Surgery 2007;14:15-26.

\section{Kjaergard 2001}

Kjaergard LL, Villumsen J, Gluud C. Reported methodologic quality and discrepancies between large and small randomized trials in meta-analysis. Annals of Internal Medicine 2001;135(11):982-9.

\section{Lundh 2012}

Lundh A, Sismondo S, Lexchin J, Busuioc OA, Bero L. Industry sponsorship and research outcome. Cochrane Database of Systematic Reviews 2012, Issue 12. [DOI: 10.1002/14651858.MR000033.pub2]

\section{Moher 1998}

Moher D, Pham B, Jones A, Cook D, Jadad AR, Moher M, et al. Does quality of reports of randomized trials affect estimates of intervention efficacy reported in meta-analyses?. Lancet 1998;352(9128):609-13.

\section{Morgan 1999}

Morgan G. Beneficial effects of NSAIDs in the gastrointestinal tract. European Journal of Gastroenterology \& Hepatology 1999;11:393-400.

\section{Mustafa 2013}

Mustafa RA, Santesso N, Brozek J, Akl EA, Walter SD, Norman G, et al. The GRADE approach is reproducible in assessing the quality of evidence of quantitative evidence syntheses. Journal of Clinical Epidemiology 2013;66(7):736-42; quiz 742.e1-5. [PUBMED: 23623694]

\section{RevMan 2014 [Computer program]}

The Nordic Cochrane Centre, Cochrane. Review Manager (RevMan). Version 5.3. Copenhagen: The Nordic Cochrane Centre, Cochrane, 2014.

\section{Royle 2003}

Royle P, Milne R. Literature searching for randomized controlled trials used in Cochrane reviews: rapid versus exhaustive searches. International Journal of Technology Assessment in Health Care 2003;19(4):591-603.

\section{Savović 2012}

Savović J, Jones HE, Altman DG, Harris RJ, Jüni P, Pildal J, et al. Influence of reported study design characteristics on intervention effect estimates from randomized, controlled trials. Health Technology Assessment 2012;16(35):1-82.

\section{Savović 2012a}

Savović J, Jones HE, Altman DG, Harris RJ, Jüni P, Pildal J, et al. Influence of reported study design characteristics on intervention effect estimates from randomized, controlled trials. Annals of Internal Medicine 2012;157(6):429-38. 


\section{Schulz 1995}

Schulz KF, Chalmer I, Hayes RS, Altman DG. Empirical evidence of bias: dimensions and methodological quality associated with estimates of treatment effects in controlled trials. JAMA 1995;273(5):408-12.

\section{Thorlund 2011}

Thorlund K, Engstrøm J, Wetterslev J, Brok J, Imberger G, Gluud C. User manual for Trial Sequential Analysis (TSA). ctu.dk/ tsa/files/tsa_manual.pdf 2011 (accessed 2 February 2015).

\section{Thornell 1985}

Thornell E, Jansson R, Svanvik J. Indomethacin reduces raised intraluminal gallbladder pressure in acute cholecystitis. Acta Chirurgica Scandinavica 1985;151:261-5.

\section{TSA 2011 [Computer program]}

Copenhagen Trial Unit. TSA - Trial Sequential Analysis. Version 0.9 Beta. Copenhagen: Copenhagen Trial Unit, 2011.

\section{Wetterslev 2008}

Wetterslev J, Thorlund K, Brok J, Gluud C. Trial sequential analysis may establish when firm evidence is reached in cumulative meta-analysis. Journal of Clinical Epidemiology 2008;61:64-75

\section{Wetterslev 2009}

Wetterslev J, Thorlund K, Brok J, Gluud C. Estimating required information size by quantifying diversity in random-effects model meta-analyses. BMC Medical Research Methodology 2009;9:86.

\section{Wood 2008}

Wood L, Egger M, Gluud LL, Schulz KF, Jüni P, Altman GD, et al. Empirical evidence of bias in treatment effect estimates in controlled trials with different interventions and outcomes: meta-epidemiological study. BMJ (Clinical Research Ed.) 2008;336:601-5.

\section{Zheng 2008}

Zheng MH, Xia HH, Chen YP. Rectal administration of NSAIDs in the prevention of post-ERCP pancreatitis: a complementary meta-analysis. Gut 2008;57:1262-7.

\section{References to other published versions of this review Colli 2007}

Colli A, Conte D, Sciola V, Fraquelli M. Non-steroid anti-inflammatory drugs for biliary cholics. Cochrane Database of Systematic Reviews 2007, Issue 1. [DOI: 10.1002/14651858.CD006390]

* Indicates the major publication for the study

\section{CHARACTERISTICS OF STUDIES}

Characteristics of included studies [ordered by study ID]

Akriviadis 1997

Methods Randomised clinical trial with parallel-group design

Participants

People with right upper quadrant or epigastric pain seen in a Greek emergency department.

The presence of gallstones was documented at ultrasonography. Criteria for exclusion: temperature > $37.5^{\circ} \mathrm{C}$, jaundice, sign of peritoneal irritation, microscopic haematuria, previous use of analgesics or antibiotic within 8 hours of enrolment, increase of serum amylases, history of peptic ulcer disease.

81 people were considered for the enrolment. 28 people were excluded as they did not meet the inclusion criteria.

Interventions

Group 1: diclofenac, single $75 \mathrm{mg}, 3 \mathrm{~mL}$ intramuscular injection (27 participants).

Group 2: saline, $3 \mathrm{~mL}$ intramuscular injection (26 participants).

All enrolled participants were admitted to the wards for a minimum of 3 days. Sequential assessment of pain response to treatment was performed every 15 minutes for the first 120 minutes, and then every 60 minutes for 8 hours. All participants were given analgesic rescue therapy with propoxyphene hydrochloride 2 hours after the initiation of the trial.

Outcomes

Lack of complete pain relief was observed in 6 out of 27 participants in the diclofenac group versus 19 out of 26 in the placebo group. Gallstone-related complications, assessed according to predefined criteria, were significantly lower in participants in diclofenac group (13/27) than in the placebo group $(21 / 26)$. Authors stated that they did not find any adverse reaction to diclofenac or placebo, even if systematically searched. 
Akriviadis 1997 (Continued)

Notes

\section{Risk of bias}

\begin{tabular}{lll}
\hline Bias & Authors' judgement & Support for judgement \\
\hline $\begin{array}{l}\text { Random sequence genera- } \\
\text { tion (selection bias) }\end{array}$ & Low risk & "Random allocation was performed using a random number table" \\
\hline $\begin{array}{l}\text { Allocation concealment } \\
\text { (selection bias) }\end{array}$ & Low risk & $\begin{array}{l}\text { "The sealed-opaque envelope method was used to conceal allocation conceal- } \\
\text { ment" }\end{array}$
\end{tabular}

Incomplete outcome data Low risk No missing outcome data.

(attrition bias)

All outcomes

\begin{tabular}{|c|c|c|}
\hline $\begin{array}{l}\text { Selective reporting (re- } \\
\text { porting bias) }\end{array}$ & Low risk & $\begin{array}{l}\text { The trial protocol is available, and all of the trial's prespecified outcomes that } \\
\text { are of interest in the review have been reported. }\end{array}$ \\
\hline
\end{tabular}

Blinding of participants Low risk $3 \mathrm{~mL}$ of diclofenac (containing $75 \mathrm{mg}$ of active principle) or $3 \mathrm{~mL}$ of saline were
and personnel (perfor- $\quad$ prepared by the pharmacist and taken to the ward to be injected. Charting of mance bias) the type of injection given was done by the pharmacist.

All outcomes

As diclofenac was slightly yellow in colour, masking of the participant was achieved by carrying the syringe with medication in a wrapped bag that was opened immediately before the injection in order that the participant could not see the syringe.

\begin{tabular}{lll}
\hline $\begin{array}{l}\text { Blinding of outcome as- } \\
\text { sessment (detection bias) } \\
\begin{array}{l}\text { All outcomes } \\
\text { Other bias }\end{array}\end{array}$ & Low risk & $\begin{array}{l}\text { "The outcome assessment was performed by the same physician/personnel } \\
\text { who administered treatment". }\end{array}$ \\
\hline
\end{tabular}

Al Waili 1998

\begin{tabular}{|c|c|}
\hline Methods & Randomised clinical trial with parallel-group design \\
\hline Participants & $\begin{array}{l}32 \text { participants ( } 26 \text { women and } 6 \text { men, mean age } 47 \text { years) presenting with acute biliary colic diagnosed } \\
\text { on the basis of physical examination, laboratory test, liver and renal function test, serum electrolytes, } \\
\text { serum amylases, and ultrasonography were enrolled. }\end{array}$ \\
\hline & $\begin{array}{l}\text { Included participants were seen at the emergency department within } 2 \text { hours of onset from their symp- } \\
\text { toms. Occurrence and severity of pain were rated on a } 5 \text {-point scale: } 0=\text { no pain; } 1=\text { mild pain; } 2=\text { mod- } \\
\text { erate pain; } 3=\text { severe pain; } 4=\text { very severe pain. Methods of random allocation were not detailed. }\end{array}$ \\
\hline
\end{tabular}

People who had received spasmolytic, pethidine, or any prostaglandin synthesis inhibitor within 2 hours were excluded from the trial, as well as those who had jaundice, liver or renal impairment, cardiovascular disease, acute cholecystitis, or history of allergy to other NSAIDs.

Pain severity and relief were recorded on a scale at 15-minute intervals for up to 1 hour, and then hourly for 12 hours.

Interventions

Group 1: tenoxicam, $20 \mathrm{mg}$ i.v. (16 participants).

Group 2: hyoscine N-butylbromide, $20 \mathrm{mg}$ i.v. (16 participants). 
Al Waili 1998 (Continued)

For both groups, an analgesic rescue therapy was planned after 1 hour with pethidine (100 mg i.v.).

Outcomes Lack of complete pain relief within 30 minutes from injection was observed in 6 out of 16 participants in the tenoxicam group versus 9 out of 16 participants in the hyoscine group.

In the tenoxicam group, pre-treatment mean pain score was $2.75 \pm 0.93$ and decreased to $0.49 \pm 0.51$ within 30 minutes. In the hyoscine group, the mean pain score was $2.62 \pm 1.01$ and decreased to $0.57 \pm$ 0.53 within 30 minutes.

No participant on tenoxicam showed complications, whereas 5 participants in the hyoscine group developed acute cholecystitis according to clinical criteria.

Drug-related adverse events were not observed in the trial.

\section{Notes}

\section{Risk of bias}

\begin{tabular}{|c|c|c|}
\hline Bias & Authors' judgement & Support for judgement \\
\hline $\begin{array}{l}\text { Random sequence genera- } \\
\text { tion (selection bias) }\end{array}$ & Unclear risk & Unclear \\
\hline $\begin{array}{l}\text { Allocation concealment } \\
\text { (selection bias) }\end{array}$ & Unclear risk & Unclear \\
\hline $\begin{array}{l}\text { Incomplete outcome data } \\
\text { (attrition bias) } \\
\text { All outcomes }\end{array}$ & Low risk & No missing outcome data. \\
\hline $\begin{array}{l}\text { Selective reporting (re- } \\
\text { porting bias) }\end{array}$ & Low risk & $\begin{array}{l}\text { The trial protocol is available, and all of the trial's prespecified outcomes that } \\
\text { are of interest in the review have been reported or similar. }\end{array}$ \\
\hline $\begin{array}{l}\text { Blinding of participants } \\
\text { and personnel (perfor- } \\
\text { mance bias) } \\
\text { All outcomes }\end{array}$ & Unclear risk & No information given. \\
\hline
\end{tabular}

Blinding of outcome as- Unclear risk No information given.

sessment (detection bias)

All outcomes

\begin{tabular}{ll}
\hline Other bias $\quad$ Low risk & $\begin{array}{l}\text { No risk of for-profit bias on the side of researchers, manufacturers, or funding } \\
\text { bodies or any personal conflicts by the authors of the trial publication were } \\
\text { observed. }\end{array}$
\end{tabular}

\section{Broggini 1984}

\begin{tabular}{ll}
\hline Methods & Randomised clinical trial with parallel-group design \\
\hline Participants & $\begin{array}{l}30 \text { consecutive outpatients (14 men and } 16 \text { women, mean age } 46 \text { years) with gallstones demonstrated } \\
\text { at ultrasonography, radiography, or at operation and presenting with biliary colic }\end{array}$ \\
\hline Interventions & Group 1: diclofenac sodium, 75 mg intramuscularly (14 participants) \\
Group 2: saline (16 participants)
\end{tabular}


Participants were randomised (methods of random allocation not detailed) to receive $75 \mathrm{mg}$ of diclofenac i.m. (14 participants) or placebo (16 participants) and followed up for 24 hours. The 2 patient groups were similar regarding age, sex, weight, duration of pain, and initial intensity of pain. Before the injection and 25 minutes afterwards, the intensity of pain was recorded on a scale where 0 represents no pain and 100 unbearable pain.

Outcomes

After 25 minutes, lack of complete pain relief was observed in 5 out of 14 participants in the diclofenac group versus 16 out of 16 participants in the placebo group. Mean pain intensity changed from $80.2 \pm$ 13.07 to $9.7 \pm 8.78$ in the diclofenac group and from $85.7 \pm 9.53$ to $86.0 \pm 9.87$ in the placebo group.

Cholelithiasis-related complications were not observed and reported.

No side effects were observed and reported in the 2 groups.

\section{Notes}

\section{Risk of bias}

\begin{tabular}{lll}
\hline Bias & Authors' judgement & Support for judgement \\
\hline $\begin{array}{l}\text { Random sequence genera- } \\
\text { tion (selection bias) }\end{array}$ & Unclear risk & Unclear \\
\hline $\begin{array}{l}\text { Allocation concealment } \\
\text { (selection bias) }\end{array}$ & Unclear risk & Unclear \\
\hline
\end{tabular}

Incomplete outcome data Low risk No missing outcome data.

(attrition bias)

All outcomes

\begin{tabular}{lll}
\hline $\begin{array}{l}\text { Selective reporting (re- } \\
\text { porting bias) }\end{array}$ & Unclear risk & $\begin{array}{l}\text { There is insufficient information to assess whether the magnitude and direc- } \\
\text { tion of the observed effect is related to selective outcome reporting. }\end{array}$ \\
\hline $\begin{array}{l}\text { Blinding of participants } \\
\text { and personnel (perfor- } \\
\text { mance bias) }\end{array}$ & Unclear risk & No information given. \\
All outcomes & \\
\hline
\end{tabular}

\begin{tabular}{lll}
\hline $\begin{array}{l}\text { Blinding of outcome as- } \\
\text { sessment (detection bias) } \\
\text { All outcomes }\end{array}$ & Unclear risk & No information given. \\
\hline Other bias & Low risk & $\begin{array}{l}\text { No risk of for-profit bias on the side of researchers, manufacturers, or funding } \\
\text { bodies or any personal conflicts by the authors of the trial publication were } \\
\text { observed. }\end{array}$ \\
\hline
\end{tabular}

Camp 1992

\begin{tabular}{ll}
\hline Methods & Randomised clinical trial with parallel-group design \\
\hline Participants & The trial included 84 people with biliary colic, presenting at emergency department. \\
& $\begin{array}{l}\text { Exclusion criteria were acute cholecystitis, pancreatitis, renal colic, hepatic or renal disease, peptic ul- } \\
\text { cer, ischaemic heart disease, and glaucoma. }\end{array}$
\end{tabular}

Interventions

Participants were allocated to 3 groups: 
Camp 1992 (Continued)

Group 1: flurbiprofen 150 mg i.m. (30 participants)

Group 2: hyoscine $20 \mathrm{mg}$ i.m. (25 participants)

Group 3: pentazocine 30 mg i.m. (29 participants)

An analgesic rescue therapy was planned. Participants were followed up for 6 hours after treatment.

Outcomes Lack of pain relief was observed in 2 out of 30 participants with flurbiprofen, 7 out of 25 participants with hyoscine, and 6 out 29 participants with pentazocine. Side effects in the flurbiprofen group were: fever (1 participant) and anxiety (1 participant); in the hyoscine group headache (1), nausea (1), dry mouth (1), and tachycardia (1 case); and in the pentazocine group: nausea (6) vomiting (4), dry mouth (1), dizziness (5).

Notes

Risk of bias

\begin{tabular}{|c|c|c|}
\hline Bias & Authors' judgement & Support for judgement \\
\hline $\begin{array}{l}\text { Random sequence genera- } \\
\text { tion (selection bias) }\end{array}$ & Low risk & Random allocation was performed using computer-generated sequences. \\
\hline $\begin{array}{l}\text { Allocation concealment } \\
\text { (selection bias) }\end{array}$ & Unclear risk & Unclear \\
\hline $\begin{array}{l}\text { Incomplete outcome data } \\
\text { (attrition bias) } \\
\text { All outcomes }\end{array}$ & Low risk & No missing outcome data. \\
\hline $\begin{array}{l}\text { Selective reporting (re- } \\
\text { porting bias) }\end{array}$ & Low risk & $\begin{array}{l}\text { The trial protocol is available and all of the trial's prespecified outcomes that } \\
\text { are of interest in the review have been reported or similar. }\end{array}$ \\
\hline $\begin{array}{l}\text { Blinding of participants } \\
\text { and personnel (perfor- } \\
\text { mance bias) } \\
\text { All outcomes }\end{array}$ & Low risk & $\begin{array}{l}\text { The person who administered the treatment was different from the one who } \\
\text { took care of the patient. }\end{array}$ \\
\hline $\begin{array}{l}\text { Blinding of outcome as- } \\
\text { sessment (detection bias) } \\
\text { All outcomes }\end{array}$ & Low risk & $\begin{array}{l}\text { The outcome assessment was performed by the same physician/personnel } \\
\text { who administered treatment. }\end{array}$ \\
\hline Other bias & Low risk & $\begin{array}{l}\text { No risk of for-profit bias on the side of researchers, manufacturers, or funding } \\
\text { bodies or any personal conflicts by the authors of the trial publication were } \\
\text { observed. }\end{array}$ \\
\hline
\end{tabular}

Dula 2001

\begin{tabular}{ll}
\hline Methods & Randomised clinical trial with parallel-group design \\
\hline Participants & $\begin{array}{l}\text { The trial enrolled participants presenting at the emergency department with symptoms consistent } \\
\text { with biliary colic and diagnosis confirmed by abdominal ultrasound. }\end{array}$ \\
& $\begin{array}{l}\text { Exclusion criteria: age less than } 18 \text { years or greater than } 65 \text { years, person's rectal temperature }>38^{\circ} \mathrm{C}, \\
\text { previous allergy to ketorolac or other NSAIDs or previous adverse reactions to pethidine, pregnancy, } \\
\text { history of renal disease, or ongoing oral anticoagulation. Enrolment was not consecutive. }\end{array}$
\end{tabular}


Dula 2001 (Continued)

30 participants were enrolled in the trial: 16 in the ketorolac group (mean age $42.5 \pm 14.3$ years; $19 \%$ males) and 14 in the pethidine group (mean age $40.6 \pm 14.3$ years; $21 \%$ males).

Interventions

Group 1: ketorolac $60 \mathrm{mg}$ i.m. (16 participants)

Group 2: pethidine $1.5 \mathrm{mg} / \mathrm{kg}$ i.m. (14 participants) with a maximum of $100 \mathrm{mg}$.

In all groups a rescue therapy was predefined, with pethidine $1 \mathrm{mg} / \mathrm{kg}$ i.m. after 30 minutes.

10-point VAS (1 to 10) was used to score pain, before and 30 minutes after treatment.

Before discharge, participants were asked to complete a questionnaire to rate the effectiveness of treatment ( 0 = no effective; $1=$ mildly effective; 2 = moderately effective; 3 = completely effective).

Outcomes

The average pain score was $7.6 \pm 1.9$ for the ketorolac group and $7.3 \pm 2.4$ for the pethidine group. 30 minutes after treatment pain score decreased to $3.8 \pm 2.6$ for the ketorolac group and $3.9 \pm 2.5$ for the pethidine group.

Regarding complications, the need for emergency cholecystectomy was also assessed. In the 2-week follow-up period this was performed in 2 participants in the pethidine group and 2 participants in the ketorolac group.

Information on adverse events was not reported.

Notes

\section{Risk of bias}

\begin{tabular}{lll}
\hline Bias & Authors' judgement & Support for judgement \\
\hline $\begin{array}{l}\text { Random sequence genera- } \\
\text { tion (selection bias) }\end{array}$ & Unclear risk & Unclear \\
\hline $\begin{array}{l}\text { Allocation concealment } \\
\text { (selection bias) }\end{array}$ & High risk & Enrollment was not consecutive \\
& $\begin{array}{l}\text { When a trial patient was identified, the emergency department nurse was in- } \\
\text { structed to refer to a posted randomised schedule in order to assign a patient } \\
\text { into a treatment group. }\end{array}$ \\
\hline
\end{tabular}

Incomplete outcome data Unclear risk Unclear. No missing outcome data.

(attrition bias)

All outcomes

\begin{tabular}{|c|c|c|}
\hline $\begin{array}{l}\text { Selective reporting (re- } \\
\text { porting bias) }\end{array}$ & Low risk & $\begin{array}{l}\text { The trial protocol is available and all of the trial's prespecified outcomes that } \\
\text { are of interest in the review have been reported or similar. }\end{array}$ \\
\hline
\end{tabular}

\begin{tabular}{|c|c|c|}
\hline $\begin{array}{l}\text { Blinding of participants } \\
\text { and personnel (perfor- } \\
\text { mance bias) } \\
\text { All outcomes }\end{array}$ & Low risk & $\begin{array}{l}\text { The physician and the patient were blinded because both medications were } \\
\text { given i.m. and only the nurse knew the identity of the medication adminis- } \\
\text { tered. }\end{array}$ \\
\hline $\begin{array}{l}\text { Blinding of outcome as- } \\
\text { sessment (detection bias) } \\
\text { All outcomes }\end{array}$ & Low risk & $\begin{array}{l}\text { The outcome assessment was performed by the same physician/personnel } \\
\text { who administered treatment. }\end{array}$ \\
\hline Other bias & Low risk & $\begin{array}{l}\text { No risk of for-profit bias on the side of researchers, manufacturers, or funding } \\
\text { bodies or any personal conflicts by the authors of the trial publication were } \\
\text { observed. }\end{array}$ \\
\hline
\end{tabular}


Goldman 2001

\begin{tabular}{ll}
\hline Methods & Randomised clinical trial with parallel-group design \\
\hline Participants & $\begin{array}{l}\text { The trial included } 60 \text { participants admitted to the emergency ward with biliary colic with gallstones } \\
\text { demonstrated by ultrasonography performed in the previous } 6 \text { months or at the emergency ward. }\end{array}$
\end{tabular}

Participants in this trial were divided into 3 groups. A fourth group of participants with low back pain was included for comparative purposes.

Group 1: average age 61 years; 12 females and 8 males

Group 2: average age 58 years; 14 females and 6 males

Group 3: average age 65 years; 10 females and 10 males

Group 4: average age 52 years; 8 females and 12 males

Exclusion criteria: temperature $>37.5^{\circ} \mathrm{C}$, signs of peritoneal inflammation, white blood count $>10.000$ / $\mathrm{mm}^{3}$ or serum amylases over the normal limit, history of peptic disease, or hypersensitivity to diclofenac.

Severity of pain was rated on a scale of $A$ to $D(A=$ mild pain; $D=$ intractable pain).

Response to drug administration was defined as: no response, improvement, or relief of pain. Inquiry as to severity of pain was done every 10 to $15 \mathrm{~min}$ by the attending internist.

Time lapse for the onset of the drug's alleviating effect and levels of response were recorded for each group.

All participants remained in emergency ward for a period of 24 hours.

Group 1: placebo (3 mL of normal saline, i.m ) (20 participants)

Group 2: papaverine $80 \mathrm{mg}$ i.m. injection (20 participants)

Group 3: diclofenac $75 \mathrm{mg}$ i.m. injection (20 participants)

Group 4: diclofenac $75 \mathrm{mg}$ i.m. injection (20 participants with low back pain)

Only group 1 and group 3 were considered in this review.

\section{Outcomes}

15 participants in the placebo group and 13 participants receiving papaverine had no improvement versus only 1 of those receiving diclofenac. On the other hand, of the participants receiving diclofenac, 17 responded with complete pain relief, 2 with partial improvement, and only 1 participant failed to respond. 5 participants treated with placebo and 4 with papaverine needed hospitalisation; all 9 of these participants progressed to acute cholecystitis. None of the participants administered diclofenac required hospitalisation or surgery within the period of observation.

Group 4, which included participants with low back pain who received diclofenac, showed pain relief in 5 participants (25\%), improvement in 7 participants (35\%), and no response in the remaining 8 participants $(40 \%)$. The trial did not report data on adverse events.

\section{Notes}

\section{Risk of bias}

\section{Bias}

Authors' judgement Support for judgement

Random sequence genera- Unclear risk Unclear

tion (selection bias) 
Goldman 2001 (Continued)

\begin{tabular}{lll}
$\begin{array}{l}\text { Allocation concealment } \\
\text { (selection bias) }\end{array}$ & Unclear risk & Unclear \\
\hline $\begin{array}{l}\text { Incomplete outcome data } \\
\text { (attrition bias) }\end{array}$ & Low risk & No missing outcome data. \\
All outcomes & &
\end{tabular}

\begin{tabular}{ll}
\hline $\begin{array}{l}\text { Selective reporting (re- } \\
\text { porting bias) }\end{array}$ & Low risk \\
& $\begin{array}{l}\text { The trial protocol is available, and all of the trial's prespecified outcomes that } \\
\text { are of interest in the review have been reported or similar. }\end{array}$
\end{tabular}

\begin{tabular}{|c|c|c|}
\hline $\begin{array}{l}\text { Blinding of participants } \\
\text { and personnel (perfor- } \\
\text { mance bias) } \\
\text { All outcomes }\end{array}$ & Low risk & $\begin{array}{l}\text { Neither the participants nor the attending intern were aware of the type of } \\
\text { drug administered. }\end{array}$ \\
\hline $\begin{array}{l}\text { Blinding of outcome as- } \\
\text { sessment (detection bias) } \\
\text { All outcomes }\end{array}$ & Low risk & $\begin{array}{l}\text { The outcome assessment was performed by the same physician/personnel } \\
\text { who administered treatment. }\end{array}$ \\
\hline Other bias & Low risk & $\begin{array}{l}\text { No risk of for-profit bias on the side of researchers, manufacturers, or funding } \\
\text { bodies or any personal conflicts by the authors of the trial publication were } \\
\text { observed. }\end{array}$ \\
\hline
\end{tabular}

\section{Grossi 1986}

Methods Randomised clinical trial with parallel-group design

Participants The trial included 54 participants presenting at the emergency department for biliary colic; diagnosis was confirmed by ultrasonography.

Exclusion criteria: hypersensitivity to NSAIDs, peptic ulcer, and bronchial asthma

Interventions
Garticipants were randomly allocated to:
Group 1: diclofenac $75 \mathrm{mg}$ i.m. (16 participants)
Group 2: butyl-scopolamine bromide $20 \mathrm{mg}$ i.m. (15 participants)
In all of the groups, a rescue therapy was planned after 60 minutes with the same drugs.
The intensity of pain was estimated before and 30 minutes after injection with an analogue chromatic
continue scale $(0$ to $100 \mathrm{~mm})$.

Outcomes Lack of pain relief was observed in 5 out of 16 participants on diclofenac and in 10 out of 15 on scopolamine.

No side effects were experienced in participants on diclofenac or scopolamine; conversely, in 3 participants on glucagon a sharp increase in glycaemia was observed without concomitant changes in serum amylase. All 3 treatments caused a significant decrease in systolic blood pressure.

No gallstone-related complications were reported.

\section{Notes}

\section{Risk of bias}


Grossi 1986 (Continued)

\begin{tabular}{|c|c|c|}
\hline Bias & Authors' judgement & Support for judgement \\
\hline $\begin{array}{l}\text { Random sequence genera- } \\
\text { tion (selection bias) }\end{array}$ & Unclear risk & Unclear \\
\hline $\begin{array}{l}\text { Allocation concealment } \\
\text { (selection bias) }\end{array}$ & Unclear risk & Unclear \\
\hline $\begin{array}{l}\text { Incomplete outcome data } \\
\text { (attrition bias) } \\
\text { All outcomes }\end{array}$ & Low risk & No missing outcome data. \\
\hline $\begin{array}{l}\text { Selective reporting (re- } \\
\text { porting bias) }\end{array}$ & Unclear risk & $\begin{array}{l}\text { There is insufficient information to assess whether the magnitude and direc- } \\
\text { tion of the observed effect is related to selective outcome reporting. }\end{array}$ \\
\hline $\begin{array}{l}\text { Blinding of participants } \\
\text { and personnel (perfor- } \\
\text { mance bias) } \\
\text { All outcomes }\end{array}$ & Low risk & $\begin{array}{l}\text { Injection was made by a member of the medical staff not involved in the sub- } \\
\text { sequent follow-up. The participant was unaware of the identity of the treat- } \\
\text { ment administered. }\end{array}$ \\
\hline $\begin{array}{l}\text { Blinding of outcome as- } \\
\text { sessment (detection bias) } \\
\text { All outcomes }\end{array}$ & Low risk & $\begin{array}{l}\text { Injection was made by a member of the medical staff not involved in the sub- } \\
\text { sequent follow-up. }\end{array}$ \\
\hline Other bias & Low risk & $\begin{array}{l}\text { No risk of for-profit bias on the side of researchers, manufacturers, or funding } \\
\text { bodies or any personal conflicts by the authors of the trial publication were } \\
\text { observed. }\end{array}$ \\
\hline
\end{tabular}

Henderson 2002

\begin{tabular}{ll}
\hline Methods & Randomised clinical trial with parallel-group design. \\
\hline Participants & $\begin{array}{l}534 \text { consecutive participants attending the emergency department with a history and physical exami- } \\
\text { nation consistent with biliary colic were enrolled. } \\
\text { Inclusion criteria: age between } 18 \text { and } 65 \text { years, pain of moderate to severe intensity on a 4-point (none, } \\
\text { mild, moderate, severe) verbal rating system, abdominal pain felt by the clinician to originate from the } \\
\text { gallbladder (e.g. right upper quadrant or epigastric pain), and a history of known cholelithiasis or a } \\
\text { bedside, emergency physician-performed ultrasonography consistent with cholelithiasis. } \\
\text { Exclusion criteria: age under } 18 \text { years or over } 65 \text { years, history of known cholecystectomy, pregnancy, } \\
\text { history of renal insufficiency, history of active peptic ulcer disease in the previous } 6 \text { months, history of } \\
\text { bleeding, anticoagulation regimen in the previous } 4 \text { weeks, immunocompromised because of different } \\
\text { underlying medical conditions (including diabetes mellitus, HIV, end-stage hepatic disease, and can- } \\
\text { cer), and a patient history of allergy to any opioid or non-opioid analgesic }\end{array}$ \\
\hline
\end{tabular}

Interventions

Of 534 enrolled participants, 324 completed the protocol and had completed study forms.

Group 1: ketorolac $30 \mathrm{mg}$ i.v. (175 participants)

Group 2: pethidine $50 \mathrm{mg}$ i.v. (149 participants)

Immediately before drug administration, participants were asked by the physician to rate the severity of their pain using a 4-point visual rating system (VRS) (none, mild, moderate, or severe) and a VAS. The VAS was a 100-millimetre horizontal, not-numbered scale bounded by the descriptors "no pain" and "maximum pain". At time 0 (baseline), the study medication was administered and vital signs were recorded. At 30 minutes, $1 \mathrm{~h}$, and $2 \mathrm{~h}$, vital signs were repeated, and the participants pain was reassessed using both the VRS and VAS. 
Henderson 2002 (Continued)

Participants with inadequate subjective pain relief at $1 \mathrm{~h}$ were given a supplementary dose of pethidine $50 \mathrm{mg}$ i.v. as a rescue drug. Also, at $2 \mathrm{~h}$ participants were asked to rate overall pain relief on a 5point categorical scale (none, a little, some, a lot, complete), and both participants and physicians were asked to rate drug tolerability (poor, fair, good, very good, or excellent).

Outcomes No significant difference in pain relief was found between the 2 groups in the VRS at 30 minutes, $1 \mathrm{~h}$, or $2 \mathrm{~h}$. No significant differences were found between the 2 groups in the change in the mean VAS at 30 minutes or at $1 \mathrm{~h}$. At 2 hours, ketorolac was equal in efficacy to pethidine for analgesia with a total change in the VAS score of $6.7 \mathrm{~cm}$ vs $6.2 \mathrm{~cm}(P=0.29)$. Lack of pain relief (i.e. the need for a further dose of pethidine) at 1 hour of observation was observed in 129 out of 175 participants treated with ketorolac versus 125 out of 149 treated with pethidine $(P=N S)$. Drowsiness was the most frequent side effect, observed in $34.6 \%$ of participants treated with ketorolac and $42.1 \%$ of those treated with pethidine $(\mathrm{P}=$ NS). Nausea and dizziness were significantly more frequent in the pethidine group than in the ketorolac group ( $16.4 \%$ vs $6.8 \%$ and $17.9 \%$ vs $6.8 \%)$.

Notes

\section{Risk of bias}

Bias Authors' judgement Support for judgement

Random sequence genera- Low risk Computed-generated list of random number.

tion (selection bias)

Allocation concealment Unclear risk Unclear

(selection bias)

Incomplete outcome data Low risk No missing outcome data

(attrition bias)

All outcomes

\begin{tabular}{|c|c|c|}
\hline $\begin{array}{l}\text { Selective reporting (re- } \\
\text { porting bias) }\end{array}$ & Low risk & $\begin{array}{l}\text { The trial protocol is available, and all of the trial's prespecified outcomes that } \\
\text { are of interest in the review have been reported. }\end{array}$ \\
\hline
\end{tabular}

\begin{tabular}{ll}
\hline $\begin{array}{l}\text { Blinding of participants } \\
\text { and personnel (perfor- }\end{array}$ & Low risk
\end{tabular}

mance bias)

All outcomes

\begin{tabular}{lll}
\hline $\begin{array}{l}\text { Blinding of outcome as- } \\
\text { sessment (detection bias) } \\
\text { All outcomes }\end{array}$ & Low risk & $\begin{array}{l}\text { The outcome assessment was performed by the same physician/personnel } \\
\text { who administered treatment. }\end{array}$ \\
\hline Other bias & Low risk & $\begin{array}{l}\text { No risk of for-profit bias on the side of researchers, manufacturers, or funding } \\
\text { bodies or any personal conflicts by the authors of the trial publication were } \\
\text { observed. }\end{array}$ \\
\hline
\end{tabular}

Kumar 2004

\begin{tabular}{ll}
\hline Methods & Randomised clinical trial with parallel-group design \\
\hline Participants & $\begin{array}{l}\text { The trial included } 72 \text { consecutive participants with biliary colic, presenting with severe pain, lasting } \\
\text { less than } 6 \mathrm{~h}, \text { attending the emergency department. The presence of gallstones was confirmed by ultra- } \\
\text { sonography. } \\
\text { Exclusion criteria were: severe pain lasting more than } 6 \mathrm{~h}, \text { fever, leucocytosis, abnormal liver function } \\
\text { tests, signs of peritonitis or ultrasound evidence of acute cholecystitis, or common bile duct stones. }\end{array}$ \\
\hline
\end{tabular}


Kumar 2004 (Continued)

The trial also excluded people who had received analgesics or antibiotics before hospital presentation, and those with pregnancy or significant systemic disease such as diabetes mellitus, uraemia, cardiovascular or respiratory disease. Similarly, people with contraindications to receive diclofenac (acute peptic ulcer, gastrointestinal bleeding, asthma or NSAID-induced allergy) or hyoscine (glaucoma, prostatic hypertrophy with urinary retention, gastrointestinal mechanical stenosis, porphyria), and those receiving medications likely to have adverse interactions with diclofenac or hyoscine (lithium, digoxin, L-Dopa, antidepressants, phenothiazines) were also excluded from the trial.

Interventions $\quad$ Group 1: diclofenac single dose of $75 \mathrm{mg}$ i.m. (36 participants)
Group 2: hyoscine-N-butylbromide single dose of $20 \mathrm{mg}$ i.m. (36 participants)
In both groups, pain severity was recorded on a 10-point VAS $30 \mathrm{~min}, 1 \mathrm{~h}, 2 \mathrm{~h}$, and $4 \mathrm{~h}$ after treatment.
Participants were then closely followed up to $72 \mathrm{~h}$ for the persistence or relapse of pain, or the de-
velopment of acute cholecystitis (which was confirmed by ultrasonography). No rescue therapy was
planned.

Outcomes

No participant in either group had complete pain relief within 1 hour from having received injection. However, the number of participants without complete pain relief at $2 \mathrm{~h}$ was significantly less frequent in the group receiving diclofenac as compared to the group receiving scopolamine (16 out of 36 versus 29 out of 36). Pain intensity by VAS decreased from $9.58 \pm 0.54$ to $5.15 \pm 1.2$ in the diclofenac group and from $9.61 \pm 0.48$ to $5.76 \pm 0.97$ in the hyoscine group.

Progression to cholecystitis was observed in 6 out of 36 participants in the diclofenac group and in 19 out of 36 participants in the hyoscine group $(P=0.003)$.

The trial did not report data on adverse events.

\section{Notes}

\section{Risk of bias}

\begin{tabular}{|c|c|c|}
\hline Bias & Authors' judgement & Support for judgement \\
\hline $\begin{array}{l}\text { Random sequence genera- } \\
\text { tion (selection bias) }\end{array}$ & Low risk & Randomized block design \\
\hline $\begin{array}{l}\text { Allocation concealment } \\
\text { (selection bias) }\end{array}$ & Unclear risk & Unclear \\
\hline $\begin{array}{l}\text { Incomplete outcome data } \\
\text { (attrition bias) } \\
\text { All outcomes }\end{array}$ & Low risk & No missing outcome data \\
\hline $\begin{array}{l}\text { Selective reporting (re- } \\
\text { porting bias) }\end{array}$ & Low risk & $\begin{array}{l}\text { The trial protocol is available, and all of the trial's prespecified outcomes of in- } \\
\text { terest to the review have been reported. }\end{array}$ \\
\hline $\begin{array}{l}\text { Blinding of participants } \\
\text { and personnel (perfor- } \\
\text { mance bias) } \\
\text { All outcomes }\end{array}$ & Unclear risk & No information given. \\
\hline $\begin{array}{l}\text { Blinding of outcome as- } \\
\text { sessment (detection bias) } \\
\text { All outcomes }\end{array}$ & Unclear risk & No information given. \\
\hline Other bias & Low risk & $\begin{array}{l}\text { No risk of for-profit bias on the side of researchers, manufacturers, or funding } \\
\text { bodies or any personal conflicts by the authors of the trial publication were } \\
\text { observed. }\end{array}$ \\
\hline
\end{tabular}


Lundstam 1985

\begin{tabular}{ll}
\hline Methods & Randomised clinical trial with parallel-group design \\
\hline Participants & $\begin{array}{l}47 \text { participants presenting at the emergency room for biliary colic pain. Only people with a confirmed } \\
\text { diagnosis of cholelithiasis (oral cholecystogram or ultrasound or operation) were included in the trial. }\end{array}$ \\
\hline Interventions & Group 1 (25 participants): diclofenac sodium (50 mg i.m.) \\
& Group 2 (22 participants): placebo (saline) (50 mg i.m.) \\
Before injection the surgeon rated the pain intensity as either moderate or severe. The analgesic ef- \\
fect was evaluated at 15 and 30 minutes as nil, partial, or complete relief. The participant also rated the \\
pain on a 100-millimetre VAS before and 30 minutes after the injection.
\end{tabular}

Outcomes Overall, at 30 minutes after injection lack of complete pain relief was observed in 14 out of 25 participants in the diclofenac group versus 16 out of 20 participants in the placebo group. Pain estimated on the visual scale was reduced by $58 \%$ (from $63 \pm 5$ to $27 \pm 5 \mathrm{~mm}$ ) in the diclofenac group and by $39 \%$ (from $66 \pm 4$ to $41 \pm 6 \mathrm{~mm}$ ) in the placebo group. As from clinical evaluation, cholecystitis developed in 8 out of 25 participants on diclofenac versus 7 out of 22 participants on saline.

No participant had evidence of common bile duct disease or pancreatitis.

No serious side effects were recorded in the 2 groups, even if a slight but significant decrease in systolic blood pressure was reported in both groups after the treatment.

Notes

\section{Risk of bias}

\begin{tabular}{|c|c|c|}
\hline Bias & Authors' judgement & Support for judgement \\
\hline $\begin{array}{l}\text { Random sequence genera- } \\
\text { tion (selection bias) }\end{array}$ & Unclear risk & Unclear \\
\hline $\begin{array}{l}\text { Allocation concealment } \\
\text { (selection bias) }\end{array}$ & Unclear risk & Unclear \\
\hline $\begin{array}{l}\text { Incomplete outcome data } \\
\text { (attrition bias) } \\
\text { All outcomes }\end{array}$ & Low risk & No missing outcome data. \\
\hline $\begin{array}{l}\text { Selective reporting (re- } \\
\text { porting bias) }\end{array}$ & Unclear risk & $\begin{array}{l}\text { There is insufficient information to assess whether the magnitude and direc- } \\
\text { tion of the observed effect is related to selective outcome reporting. }\end{array}$ \\
\hline $\begin{array}{l}\text { Blinding of participants } \\
\text { and personnel (perfor- } \\
\text { mance bias) } \\
\text { All outcomes }\end{array}$ & Low risk & No information given. \\
\hline $\begin{array}{l}\text { Blinding of outcome as- } \\
\text { sessment (detection bias) } \\
\text { All outcomes }\end{array}$ & Low risk & No information given. \\
\hline Other bias & Low risk & $\begin{array}{l}\text { No risk of for-profit bias on the side of researchers, manufacturers, or funding } \\
\text { bodies or any personal conflicts by the authors of the trial publication were } \\
\text { observed. }\end{array}$ \\
\hline
\end{tabular}


Magrini 1985

\begin{tabular}{ll}
\hline Methods & Randomised clinical trial \\
\hline Participants & 60 participants presenting at 2 Italian emergency wards with biliary colic were enrolled. \\
& Exclusion criteria were: a history of haemorrhagic disorder; peptic ulcer; severe hepatic, renal respira- \\
& tory, or cardiac insufficiency; and diabetes mellitus. Severely disabled people, people unable to co-op- \\
erate, narcotic addicts, people with known hypersensitivity to ketoprofen or acetylsalicylic-acid were \\
also excluded.
\end{tabular}

Pain intensity was assessed before and 15, 30, 60, 120, and 180 minutes after treatment by asking the participants to rate pain according to a 5 -point scale $(0=$ none, $1=$ mild, $2=$ moderate, $3=$ severe, $4=$ very severe).

Rescue analgesic therapy was planned after 3 hours from the beginning of the trial with the same drug.

Interventions

Group 1: ketoprofen $200 \mathrm{mg}$ i.v. (20 participants)

Group 2: lysine acetylsalicylate, $1.8 \mathrm{~g}$ i.v. (20 participants)

Group 3: placebo $10 \mathrm{~mL}$ i.v. (20 participants)

Only group 1 and group 3 were considered in this review.

Outcomes

30 minutes after injection, lack of complete pain relief was observed in 3 out of 20 participants in ketoprofen group, 4 out of 20 participants in the lysine acetylsalicylic-acid group, and 16 out of 20 participants in the placebo group.

All treatments were well tolerated.

Only 1 participant experienced vomiting (in the acetylsalicylic-acid group) and 1 drowsiness (in the ketoprofen group). No complication was reported.

Adverse events were: restlessness ( 2 with placebo and 1 with acetylsalicylic-acid), vomiting (1 participant with acetylsalicylic-acid), and drowsiness (1 case with ketoprofen). Blood pressure was slightly but significantly decreased in the 2 treatment groups but not in the placebo subset.

Notes

\section{Risk of bias}

Bias Authors' judgement Support for judgement

Random sequence genera- Unclear risk Unclear

tion (selection bias)

\begin{tabular}{lll}
\hline $\begin{array}{l}\text { Allocation concealment } \\
\text { (selection bias) }\end{array}$ & Unclear risk & Unclear \\
\hline $\begin{array}{l}\text { Incomplete outcome data } \\
\text { (attrition bias) } \\
\text { All outcomes }\end{array}$ & Low risk & No missing outcome data. \\
\hline
\end{tabular}

\begin{tabular}{|c|c|c|}
\hline $\begin{array}{l}\text { Selective reporting (re- } \\
\text { porting bias) }\end{array}$ & Unclear risk & $\begin{array}{l}\text { There is insufficient information to assess whether the magnitude and direc- } \\
\text { tion of the observed effect is related to selective outcome reporting. }\end{array}$ \\
\hline
\end{tabular}

\begin{tabular}{|c|c|c|}
\hline $\begin{array}{l}\text { Blinding of participants } \\
\text { and personnel (perfor- } \\
\text { mance bias) }\end{array}$ & Low risk & $\begin{array}{l}\text { The } 3 \text { drugs were given from identical vials of identical appearance, containing } \\
\text { a freeze-dried powder to be dissolved in } 10 \mathrm{~mL} \text { sterile water and injected in a } \\
\text { 2-minutes intravenous dose. }\end{array}$ \\
\hline
\end{tabular}


Magrini 1985 (Continued)

All outcomes

\begin{tabular}{lll}
\hline $\begin{array}{l}\text { Blinding of outcome as- } \\
\text { sessment (detection bias) } \\
\text { All outcomes }\end{array}$ & Low risk & $\begin{array}{l}\text { The outcome assessment was performed by the same physician/personnel } \\
\text { who administered treatment. }\end{array}$ \\
\hline Other bias & Low risk & $\begin{array}{l}\text { No risk of for-profit bias on the side of researchers, manufacturers, or funding } \\
\text { bodies or any personal conflicts by the authors of the trial publication were } \\
\text { observed. }\end{array}$
\end{tabular}

Olsen 2008

\begin{tabular}{ll}
\hline Methods & Randomised clinical trial \\
\hline Participants & $\begin{array}{l}51 \text { participants presenting with suspected biliary colic, } 5 \text { of them refused and thus } 46 \text { were enrolled } \\
\text { and randomised. }\end{array}$ \\
\hline Interventions & - ketorolac $30 \mathrm{mg}$ i.v. (21 participants) \\
& - butorphanol $1 \mathrm{mg}$ i.v. (25 participants) \\
\hline Outcomes & $\begin{array}{l}\text { Pain level was assessed using 1-to-10 "faces" visual analogue pain scale basal and at } 15 \text { and } 30 \text { minutes } \\
\text { after medication infusion. }\end{array}$ \\
\hline Notes & \\
\hline
\end{tabular}

\section{Risk of bias}

\begin{tabular}{|c|c|c|}
\hline Bias & Authors' judgement & Support for judgement \\
\hline $\begin{array}{l}\text { Random sequence genera- } \\
\text { tion (selection bias) }\end{array}$ & Low risk & $\begin{array}{l}\text { The pharmacy supplied the participants with their medication via a comput- } \\
\text { ed-generated randomisation sequence. }\end{array}$ \\
\hline $\begin{array}{l}\text { Allocation concealment } \\
\text { (selection bias) }\end{array}$ & Low risk & Medicaments were given by a nurse uninvolved in the study. \\
\hline $\begin{array}{l}\text { Incomplete outcome data } \\
\text { (attrition bias) } \\
\text { All outcomes }\end{array}$ & Low risk & No missing outcome data. \\
\hline $\begin{array}{l}\text { Selective reporting (re- } \\
\text { porting bias) }\end{array}$ & Unclear risk & $\begin{array}{l}\text { There is insufficient information to assess whether the magnitude and direc- } \\
\text { tion of the observed effect is related to selective outcome reporting. }\end{array}$ \\
\hline $\begin{array}{l}\text { Blinding of participants } \\
\text { and personnel (perfor- } \\
\text { mance bias) } \\
\text { All outcomes }\end{array}$ & Low risk & $\begin{array}{l}\text { The treating physician and the participants were blind to the study medication } \\
\text { used. At the end of the study, when all the participants were enrolled and data } \\
\text { collected, the pharmacy provided information as to which study drug was ac- } \\
\text { tually administered to each participant. }\end{array}$ \\
\hline $\begin{array}{l}\text { Blinding of outcome as- } \\
\text { sessment (detection bias) } \\
\text { All outcomes }\end{array}$ & Low risk & $\begin{array}{l}\text { Drug administration was made by a nurse not involved in the subsequent fol- } \\
\text { low-up. }\end{array}$ \\
\hline Other bias & Low risk & $\begin{array}{l}\text { No risk of for-profit bias on the side of researchers, manufacturers, or funding } \\
\text { bodies or any personal conflicts by the authors of the trial publication were } \\
\text { observed. }\end{array}$ \\
\hline
\end{tabular}


ED: emergency department; i.m.: intramuscularly; i.v.: intravenously; NS: non-significant; NSAIDs: non-steroid anti-inflammatory drugs; VAS: visual analogue scale.

Hyoscine butylbromide, butyl-scopolamine bromide, and scopolamine is the one and the same drug.

Characteristics of excluded studies [ordered by study ID]

\begin{tabular}{ll}
\hline Study & Reason for exclusion \\
\hline Chang 2002 & Not relevant as it refers to dental pain. \\
\hline Chaudhary 1999 & The study compares 2 NSAIDs. \\
\hline Kantor 1986 & It is a review. \\
\hline Marsala 1986 & The study compares a different type of administration of naproxen sodium (i.v. versus i.m.). \\
\hline Niinikoski 1984 & The study compares 2 NSAIDs. \\
\hline Thornell 1979 & It is not a randomised clinical trial. \\
\hline
\end{tabular}

i.m.: intramuscularly; i.v.: intravenously; NSAIDs: non-steroid anti-inflammatory drugs

Characteristics of ongoing studies [ordered by study ID]

NCT02268955

\section{Trial name or title}

Methods

\section{Participants}

Interventions

Outcomes

Outcomes

Assessment of the analgesic efficacy of intravenous ibuprofen in biliary colic

Randomised clinical trial

Patients referring at the emergency department for biliary colic

Drug: ibuprofen i.v.; placebo: saline

Primary: pain level: VAS at 15 minutes post-administration

Secondary: changes in pain level (VAS) at 30, 45, 60, and 90 minutes post-administration

\begin{tabular}{ll}
\hline Starting date & 16 September 2014 \\
\hline Contact information & Dr Dan Quan by phone \\
& Dr Mary Mulrow by phone \\
\hline Notes & Eligibility 18.55 years \\
\hline
\end{tabular}

i.v.: intravenously; VAS: visual analogue scale.

\section{DATA AND ANALYSES}


Comparison 1. NSAIDs versus placebo

\begin{tabular}{lllll}
\hline Outcome or subgroup title & No. of studies & $\begin{array}{l}\text { No. of partici- } \\
\text { pants }\end{array}$ & Statistical method & Effect size \\
\hline 1 Lack of pain relief & 5 & 208 & Risk Ratio (M-H, Fixed, 95\% Cl) & $0.27[0.19,0.40]$ \\
\hline $\begin{array}{l}2 \text { Cholelithiasis-related complica- } \\
\text { tions }\end{array}$ & 3 & 140 & $\begin{array}{l}\text { Risk Ratio (M-H, Random, 95\% } \\
\mathrm{Cl})\end{array}$ & $0.66[0.38,1.15]$ \\
\hline
\end{tabular}

Analysis 1.1. Comparison 1 NSAIDs versus placebo, Outcome 1 Lack of pain relief.

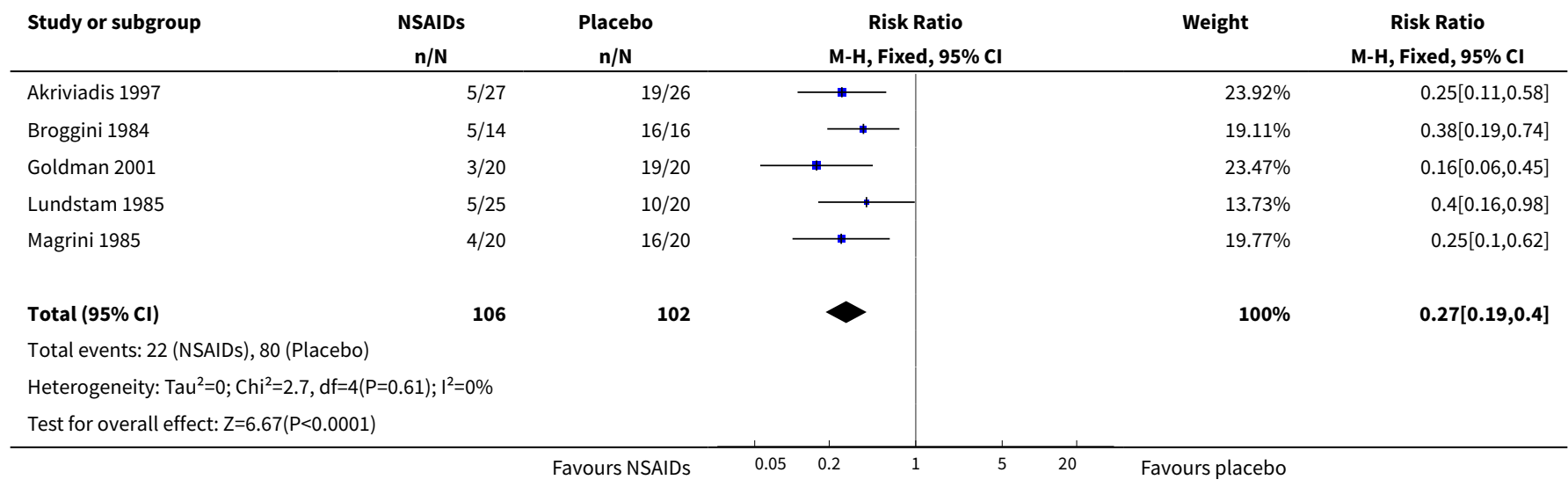

Analysis 1.2. Comparison 1 NSAIDs versus placebo, Outcome 2 Cholelithiasis-related complications.

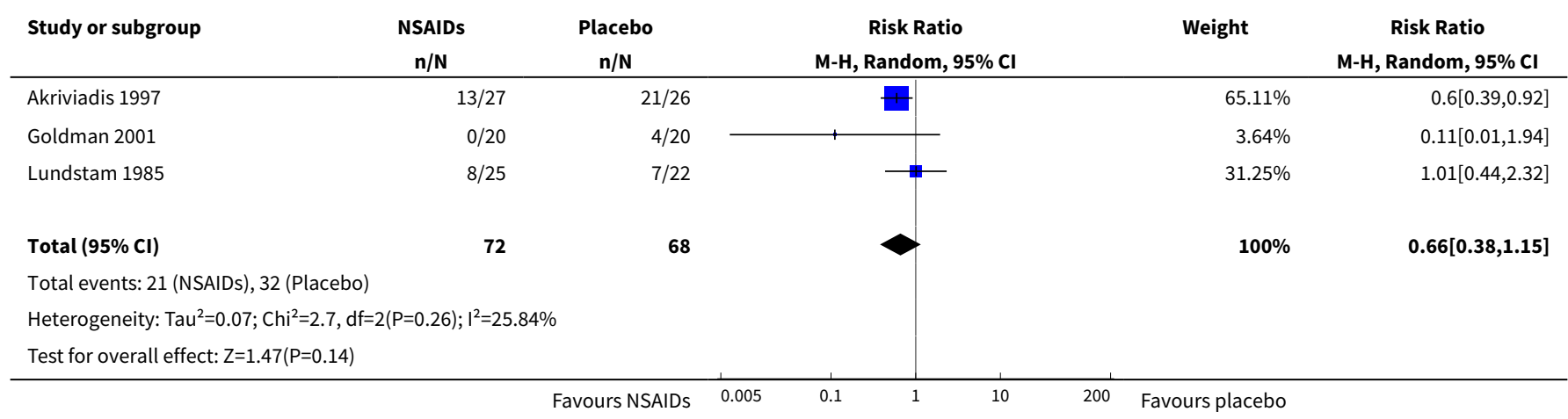

\section{Comparison 2. NSAIDs versus opioids}

\begin{tabular}{lllll}
\hline Outcome or subgroup title & No. of studies & $\begin{array}{l}\text { No. of partici- } \\
\text { pants }\end{array}$ & Statistical method & Effect size \\
\hline 1 Lack of pain relief & 4 & 459 & $\begin{array}{l}\text { Risk Ratio (M-H, Random, 95\% } \\
\text { Cl) }\end{array}$ & $0.98[0.47,2.07]$
\end{tabular}




\begin{tabular}{lllll}
\hline Outcome or subgroup title & No. of studies & $\begin{array}{l}\text { No. of partici- } \\
\text { pants }\end{array}$ & Statistical method & Effect size \\
\hline $\begin{array}{l}2 \text { Cholelithiasis-related complica- } \\
\text { tions }\end{array}$ & 1 & $\begin{array}{l}\text { Risk Ratio (M-H, Random, 95\% } \\
\text { Cl) }\end{array}$ & Totals not selected \\
\hline
\end{tabular}

Analysis 2.1. Comparison 2 NSAIDs versus opioids, Outcome 1 Lack of pain relief.

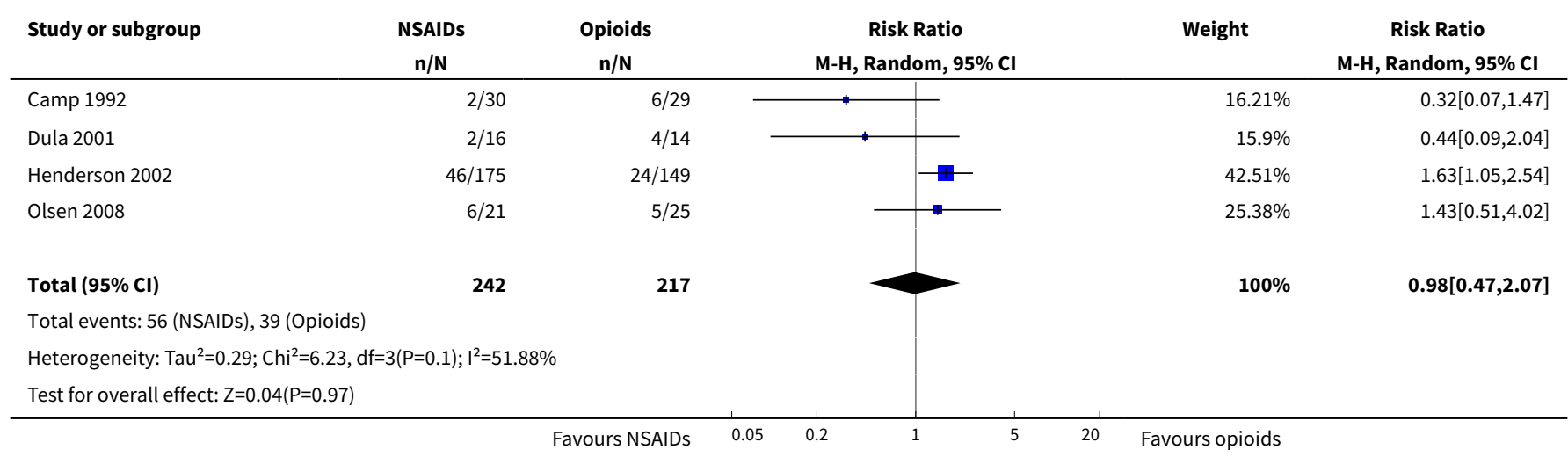

Analysis 2.2. Comparison 2 NSAIDs versus opioids, Outcome 2 Cholelithiasis-related complications.

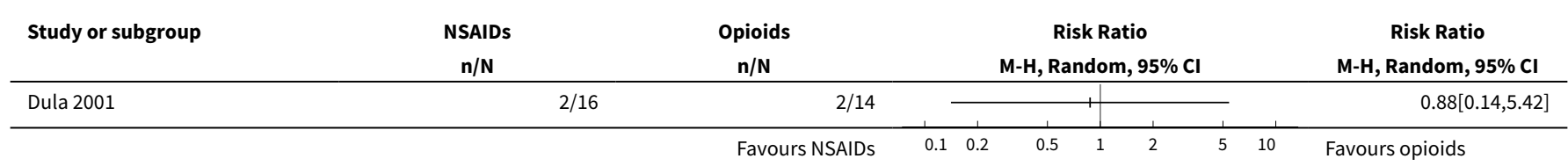

\section{Comparison 3. NSAIDs versus spasmolytic drugs}

\begin{tabular}{lllll}
\hline Outcome or subgroup title & No. of studies & $\begin{array}{l}\text { No. of partici- } \\
\text { pants }\end{array}$ & Statistical method & Effect size \\
\hline 1 Lack of pain relief & 4 & 190 & Risk Ratio (M-H, Fixed, 95\% Cl) & $0.51[0.37,0.71]$ \\
\hline $\begin{array}{l}2 \text { Cholelithiasis-related complica- } \\
\text { tions }\end{array}$ & 2 & 104 & Risk Ratio (M-H, Fixed, 95\% Cl) & $0.27[0.12,0.57]$ \\
\hline
\end{tabular}

Analysis 3.1. Comparison 3 NSAIDs versus spasmolytic drugs, Outcome 1 Lack of pain relief.

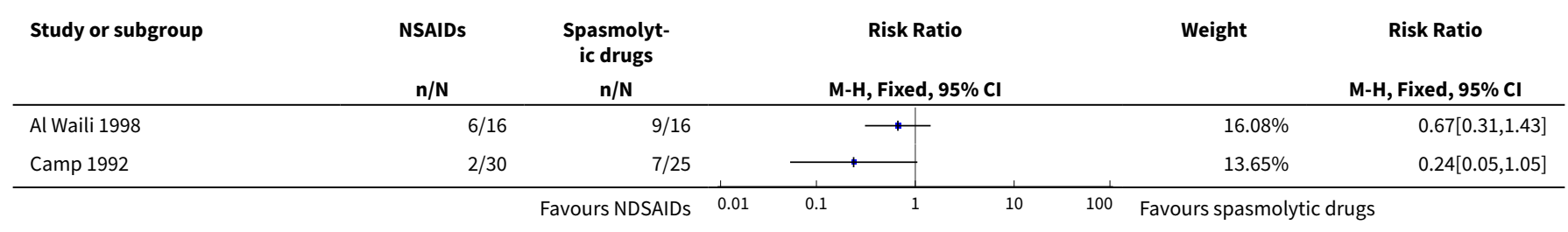




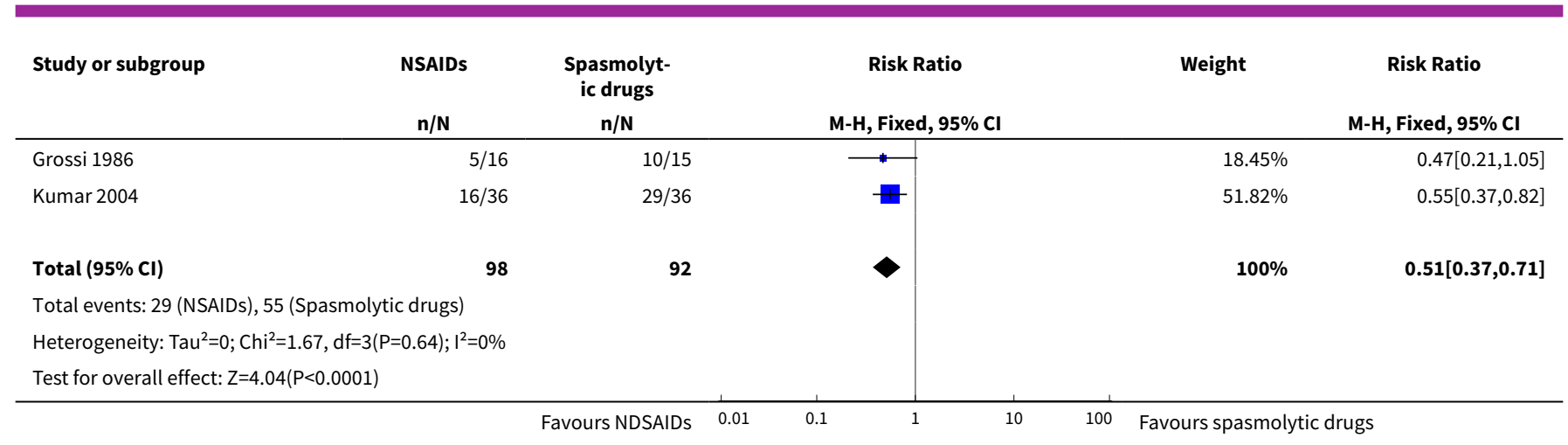

\section{Analysis 3.2. Comparison 3 NSAIDs versus spasmolytic drugs, Outcome 2 Cholelithiasis-related complications.}

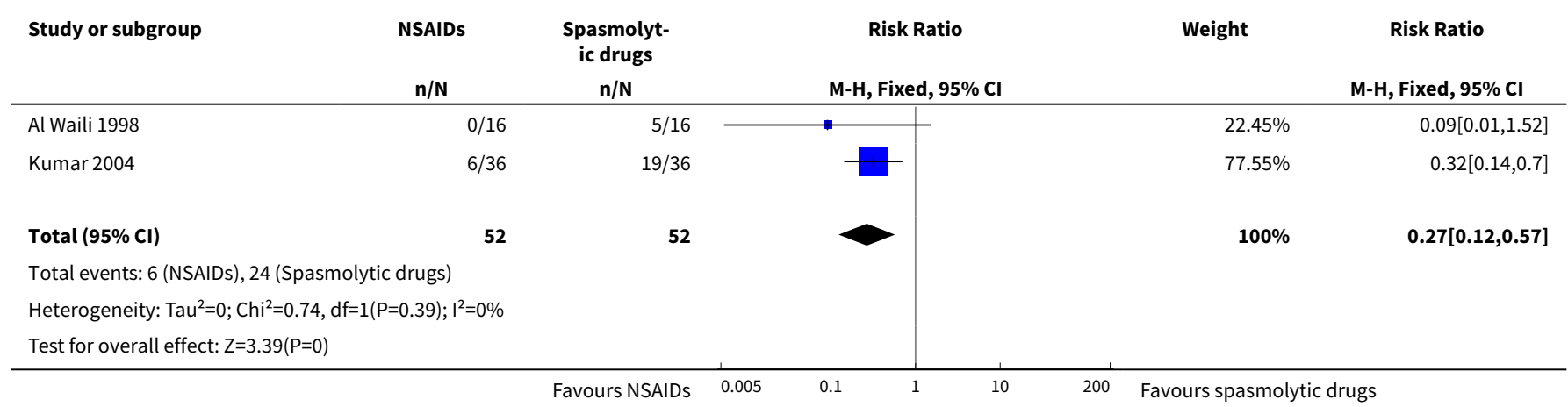

\section{APPENDICES}

\section{Appendix 1. Search strategies}

\begin{tabular}{|c|c|c|}
\hline Database & Date of search & Search terms \\
\hline $\begin{array}{l}\text { The Cochrane Hepa- } \\
\text { to-Biliary Group Con- } \\
\text { trolled Trials Register }\end{array}$ & 31 July 2016 & Anti-inflammatory or NSAID and (biliary colic or gall bladder or cholelithiasis) \\
\hline $\begin{array}{l}\text { Cochrane Central Regis- } \\
\text { ter of Controlled Trials } \\
\text { (CENTRAL) (Cochrane } \\
\text { Library) }\end{array}$ & 2016, Issue 5 & $\begin{array}{l}\text { \#1 MeSH descriptor Anti-Inflammatory Agents, Non-Steroidal explode all trees } \\
\text { \#2 (anti-inflammatory agent) and (non-steroid }{ }^{\star} \text { ) } \\
\text { \#3 NSAID* } \\
\text { \#4 (\#1 OR \#2 OR \#3) } \\
\text { \#5 MeSH descriptor Biliary Tract Diseases explode all trees } \\
\text { \#6 MeSH descriptor Colic explode all trees } \\
\text { \#7 (\#5 AND \#6) } \\
\text { \#8 (biliary colic*) } \\
\# 9 \text { (\#7 OR \#8) } \\
\# 10(\# 4 \text { AND \#9) }\end{array}$ \\
\hline
\end{tabular}


\#3 \#1 or \#2

\#4 biliary colic * or biliary disease* or biliary pain *

\#5 biliary complication* or biliary colic* complication* or acute cholecystitis or cholelithiasis-related complication* or acute pancreatitis or cholangitis or jaundice

\#6 \#4 or \#5

\#7 \#3 and \#6

\#8 random* or placebo* or blind* or meta-analys ${ }^{\star}$ or Randomized controlled trial $^{\star}$ or randomised clinical trial or controlled trial ${ }^{\star}$ or quasi randomized trial ${ }^{\star}$ \#9 \#7 and \#8

\begin{tabular}{|c|c|c|}
\hline Embase (Ovid SP) & 1974 to 31 July 2016 & 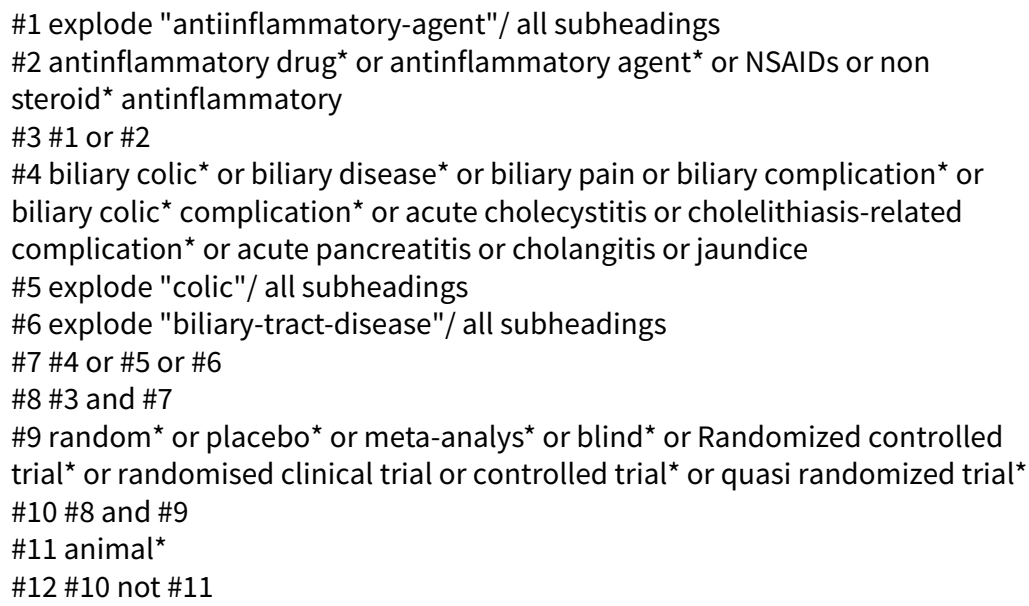 \\
\hline $\begin{array}{l}\text { Science Citation In- } \\
\text { dex Expanded (Web of } \\
\text { Science) }\end{array}$ & 1900 to 31 July 2016 & $\begin{array}{l}\text { \#5 \#3 and \#4 } \\
\text { \#4 TS=biliary colic* } \\
\text { \#3 6\#1 or \#2 } \\
\text { \#2 TS=NSAID* } \\
\# 1 \text { TS=(Anti-Inflammatory Agent* and Non-Steroid*) }\end{array}$ \\
\hline
\end{tabular}

\section{CONTRIBUTIONS OFAUTHORS}

Mirella Fraquelli: conception and design, drafting, and final revision of the review. Giovanni Casazza: Trial Sequential Analysis and drafting of the review.

Dario Conte: conception and design, and drafting of the review.

Agostino Colli: conception and design, and drafting of the review.

All authors approved the current review version for publication.

\section{DECLARATIONS OF INTEREST}

Mirella Fraquelli: none known.

Giovanni Casazza: none known.

Dario Conte: none known.

Agostino Colli: none known.

\section{SOURCES OF SUPPORT}

\section{Internal sources}

- Università degli Studi di Milano, Milan, Italy.

- A Manzoni Hospital ASST Lecco, Lecco, Italy.

\section{External sources}

- No sources of support supplied 


\section{DIFFERENCES BETWEEN PROTOCOLAND REVIEW}

The main outcome as stated in the protocol was initially pain relief (Colli 2007). One of the peer reviewers suggested changing the outcome into the proportion of participants who had 'lack of pain relief', and we agreed to this. We thus divided outcomes into primary (1. mortality and 2. lack of pain relief) and secondary (1. number of people with cholelithiasis-related complications (e.g. acute cholecystitis, acute pancreatitis, jaundice, cholangitis; number of people manifesting bleeding from operative intervention or ERCP less than 9, or both; 2. quality of life; 3. drug-related complications and adverse events, expressed as the number of people experiencing any event (e.g. gastrointestinal bleeding, cutaneous rash, renal function impairment, cardiovascular events, and any other described in the trials); 4. quantification of pain relief in which intensity of pain was rated in the trials on a quantitative scale in the following way: the difference of pain intensity after 30 or 60 minutes from treatment compared with pain intensity at enrolment. Differences in the scale used for rating pain were accounted for by multiplying by 10 for the 10-point scale, by 20 for the five-point scale, and by 25 for the four-point scale. We left unchanged scales in which pain was rated on a 100-millimetre analogue chromatic rating system (data synthesis or extraction); 5. the time needed to obtain pain relief: complete pain relief or any small amount of pain relief (as defined by the different trials).

We have added information about Trial Sequential Analysis at the review stage, as at the time of the protocol preparation it was not completely developed.

We have added the incomplete outcome data 'Risk of bias' domain to the 'Risk of bias' assessment. 